VITRINITE REFLECTANCE DATA

ON

34 AIASKAN COAL SAMPLES 


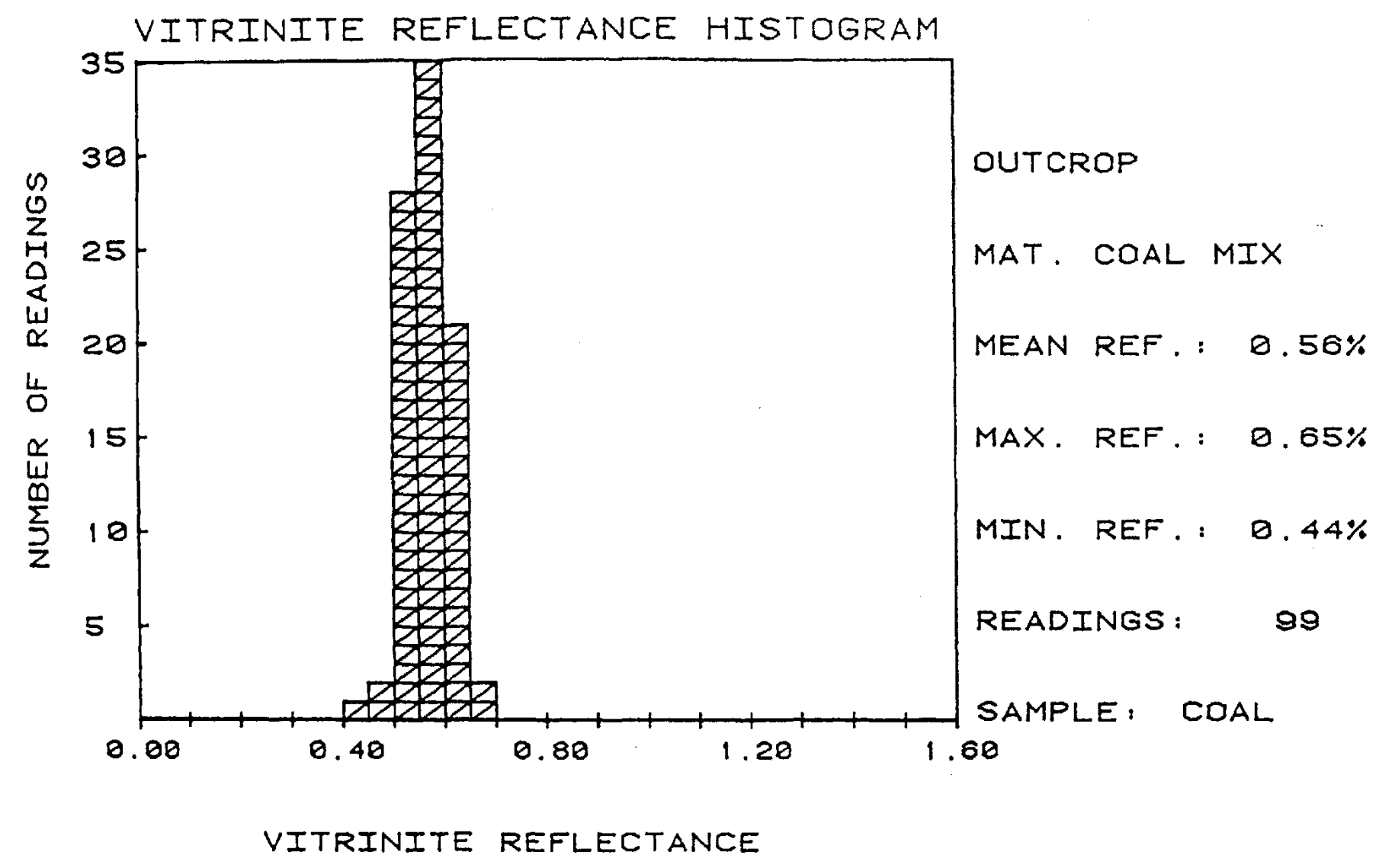

VITRINITE REFLECTANCE DATA

\begin{tabular}{|c|c|c|c|c|c|c|c|c|c|c|c|}
\hline Ro & Ct. & Ro & Ct. & Ro & $c t$. & Ro & Ct. & Ro & Ct. & Ro & Ct. \\
\hline $\begin{array}{l}0.40 \\
0.46 \\
0.52 \\
0.58 \\
0.64\end{array}$ & $\begin{array}{l}0 \\
0 \\
7 \\
5 \\
4\end{array}$ & $\begin{array}{l}0.41 \\
0.47 \\
0.53 \\
0.59 \\
0.65\end{array}$ & $\begin{array}{l}0 \\
0 \\
9 \\
5 \\
2\end{array}$ & $\begin{array}{l}0.42 \\
0.48 \\
0.54 \\
0.60 \\
0.00\end{array}$ & $\begin{array}{l}0 \\
0 \\
5 \\
5 \\
0\end{array}$ & $\begin{array}{l}0.43 \\
0.49 \\
0.55 \\
0.61 \\
0.00\end{array}$ & $\begin{array}{r}0 \\
2 \\
13 \\
4 \\
0\end{array}$ & $\begin{array}{l}0.44 \\
0.50 \\
0.56 \\
0.62 \\
0.00\end{array}$ & $\begin{array}{l}1 \\
2 \\
8 \\
5 \\
0\end{array}$ & $\begin{array}{l}0.45 \\
0.51 \\
0.57 \\
0.63 \\
0.00\end{array}$ & $\begin{array}{r}0 \\
5 \\
14 \\
3 \\
0\end{array}$ \\
\hline
\end{tabular}




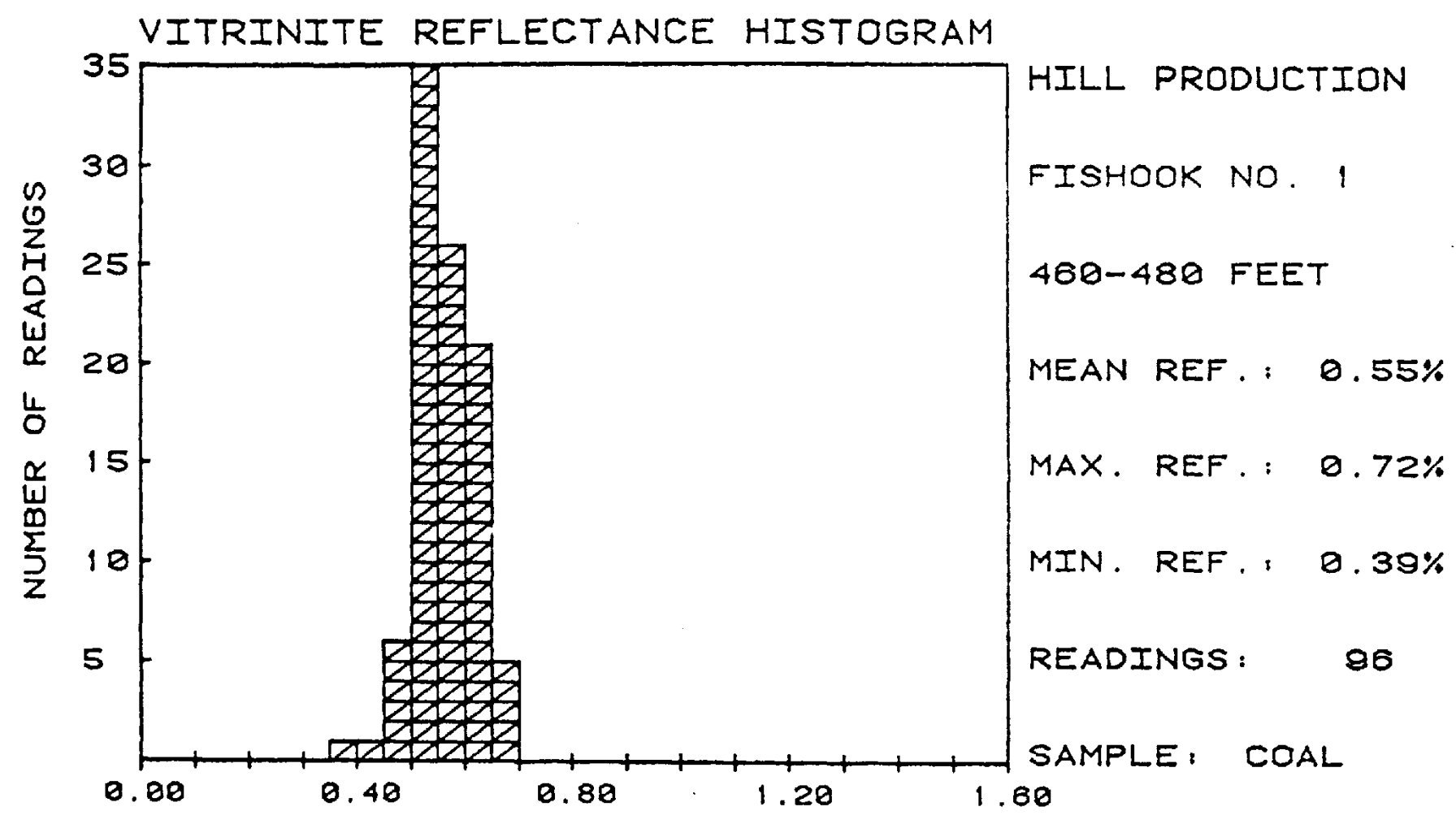

VITRINITE REFLECTANCE

VITRINITE REFLECTANCE DATA

$\begin{array}{ll}\text { Ro } & C t \\ 0.35 & 0 \\ 0.41 & 0 \\ 0.47 & 1 \\ 0.53 & 5 \\ 0.59 & 4 \\ 0.65 & 2 \\ 0.71 & 0\end{array}$

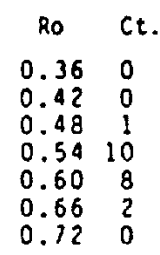

$\begin{array}{ll}\text { Ro } & \text { Ct. } \\ 0.37 & 0 \\ 0.43 & 0 \\ 0.49 & 3 \\ 0.55 & 8 \\ 0.61 & 6 \\ 0.67 & 0 \\ 0.00 & 0\end{array}$

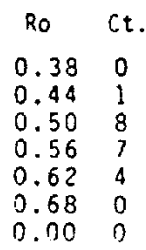

$\begin{array}{ll}\text { Ro } & \text { Ct. } \\ 0.39 & 1 \\ 0.45 & 1 \\ 0.51 & 8 \\ 0.57 & 5 \\ 0.63 & 1 \\ 0.69 & 1 \\ 0.00 & 0\end{array}$

Ro ct.

0.40 .0

$0.46 \quad 0$

0.525

$\begin{array}{ll}0.64 & 2 \\ 0.70 & 0 \\ 0.00 & 0\end{array}$ 


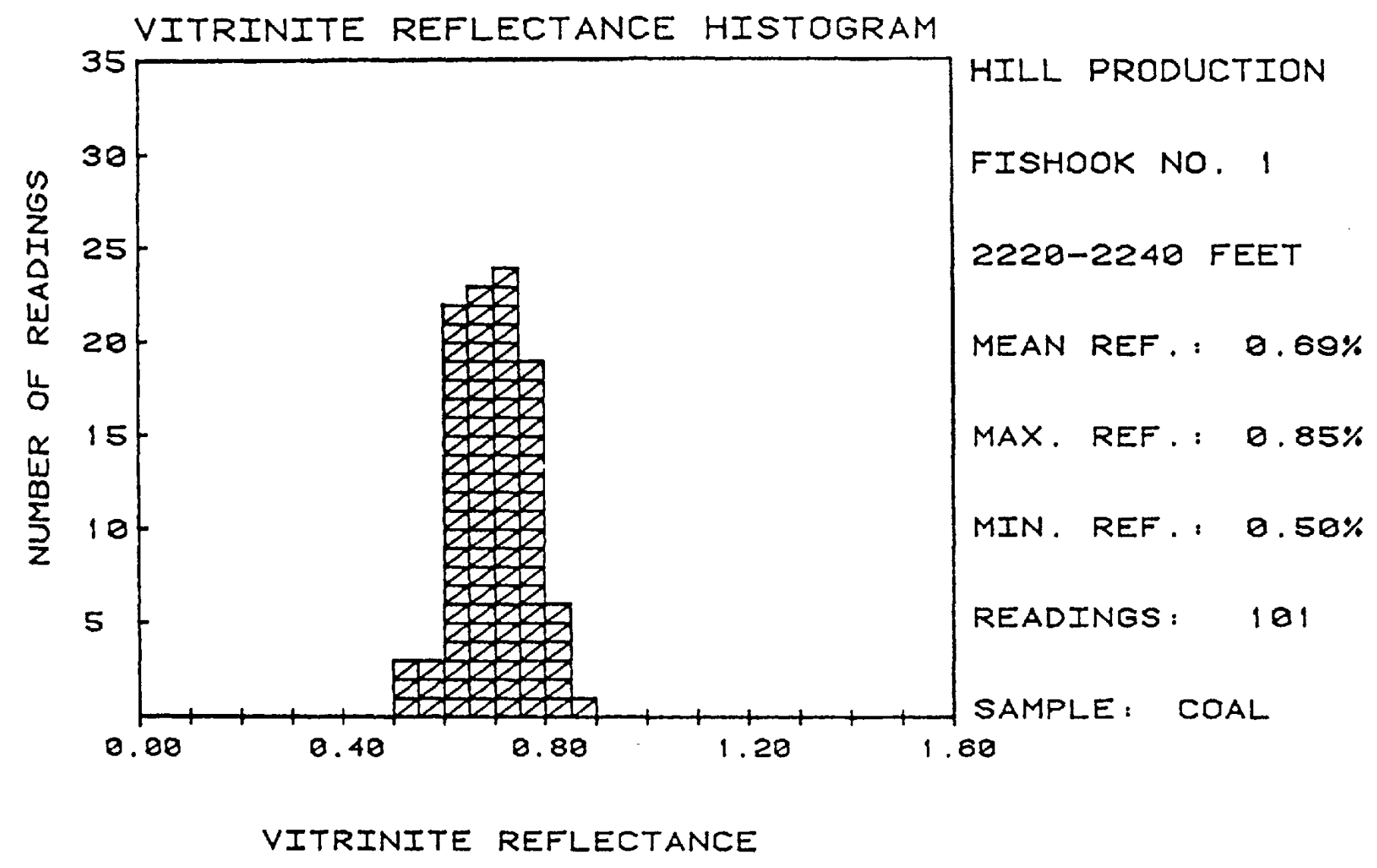

VITRINITE REFLECTANCE DATA

$\begin{array}{ll}\text { Ro } & C t . \\ 0.45 & 0 \\ 0.51 & 0 \\ 0.57 & 0 \\ 0.63 & 5 \\ 0.69 & 2 \\ 0.75 & 1 \\ 0.81 & 0\end{array}$

$\begin{array}{cl}\text { RO } & \text { Ct. } \\ 0.46 & 0 \\ 0.52 & 0 \\ 0.58 & 0 \\ 0.64 & 5 \\ 0.70 & 4 \\ 0.76 & 5 \\ 0.82 & 1\end{array}$

$\begin{array}{cc}\text { Ro } & C t \\ 0.47 & 0 \\ 0.53 & 0 \\ 0.59 & 3 \\ 0.65 & 3 \\ 0.71 & 7 \\ 0.77 & 3 \\ 0.83 & 2\end{array}$

$\begin{array}{cc}\text { Ro } & c t . \\ 0.48 & 0 \\ 0.54 & 1 \\ 0.60 & 5 \\ 0.66 & 4 \\ 0.72 & 6 \\ 0.78 & 0 \\ 0.84 & 0\end{array}$

$\begin{array}{ll}80 & C t . \\ 0.49 & 0 \\ 0.55 & 0 \\ 0.61 & 1 \\ 0.67 & 7 \\ 0.73 & 5 \\ 0.79 & 4 \\ 0.85 & 1\end{array}$

Ro $c t$.

0.502

0.560

0.626

$0.68 ?$
0.74

0.803 


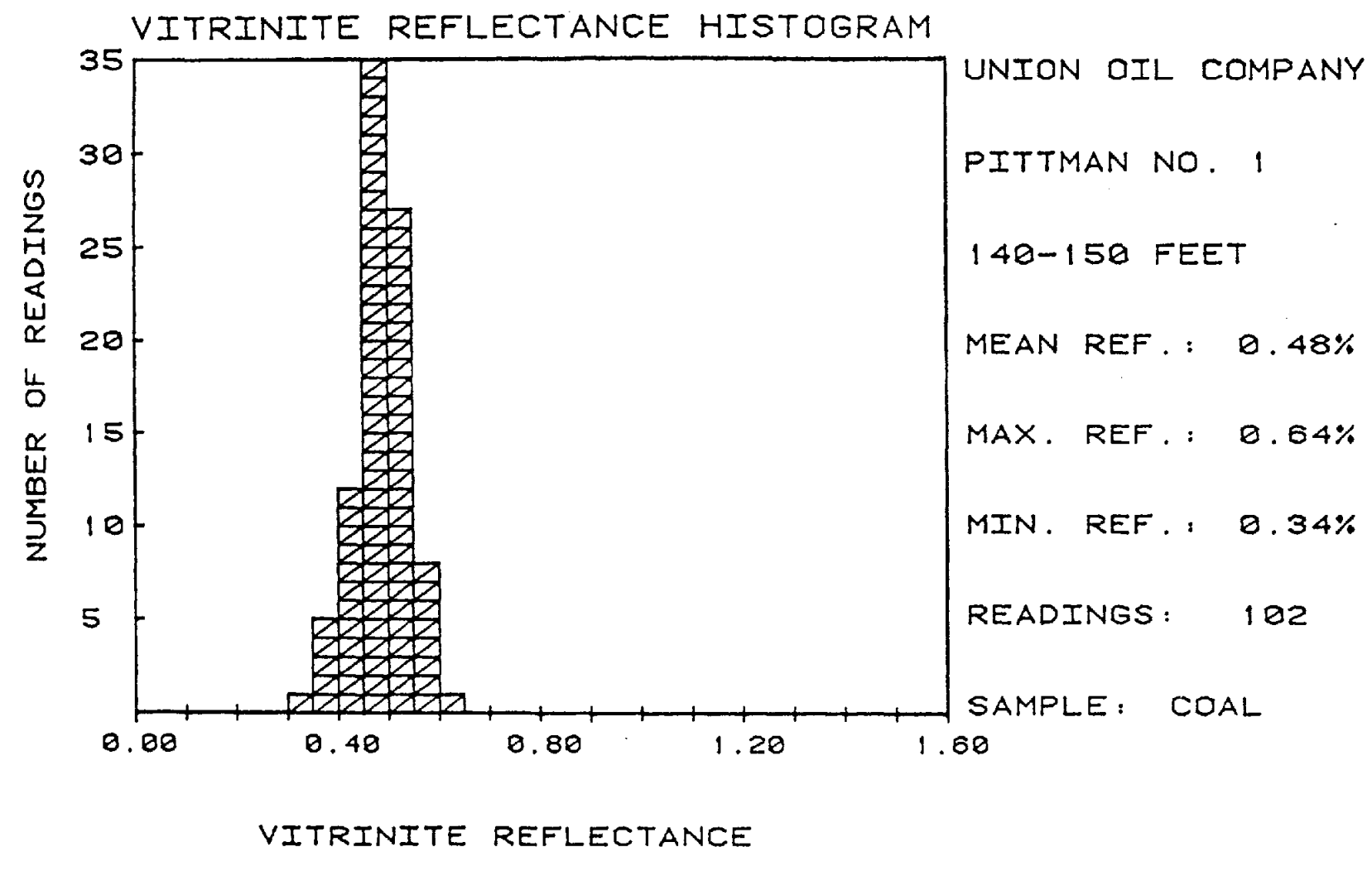

VITRINITE REFLECTANCE DATA
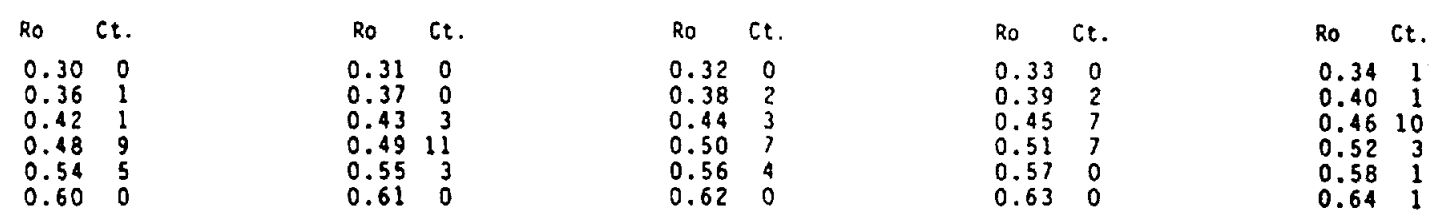

$\begin{array}{lr}\text { Ro } & C t . \\ 0.35 & 0 \\ 0.41 & 4 \\ 0.47 & 11 \\ 0.53 & 5 \\ 0.59 & 0 \\ 0.00 & 0\end{array}$ 


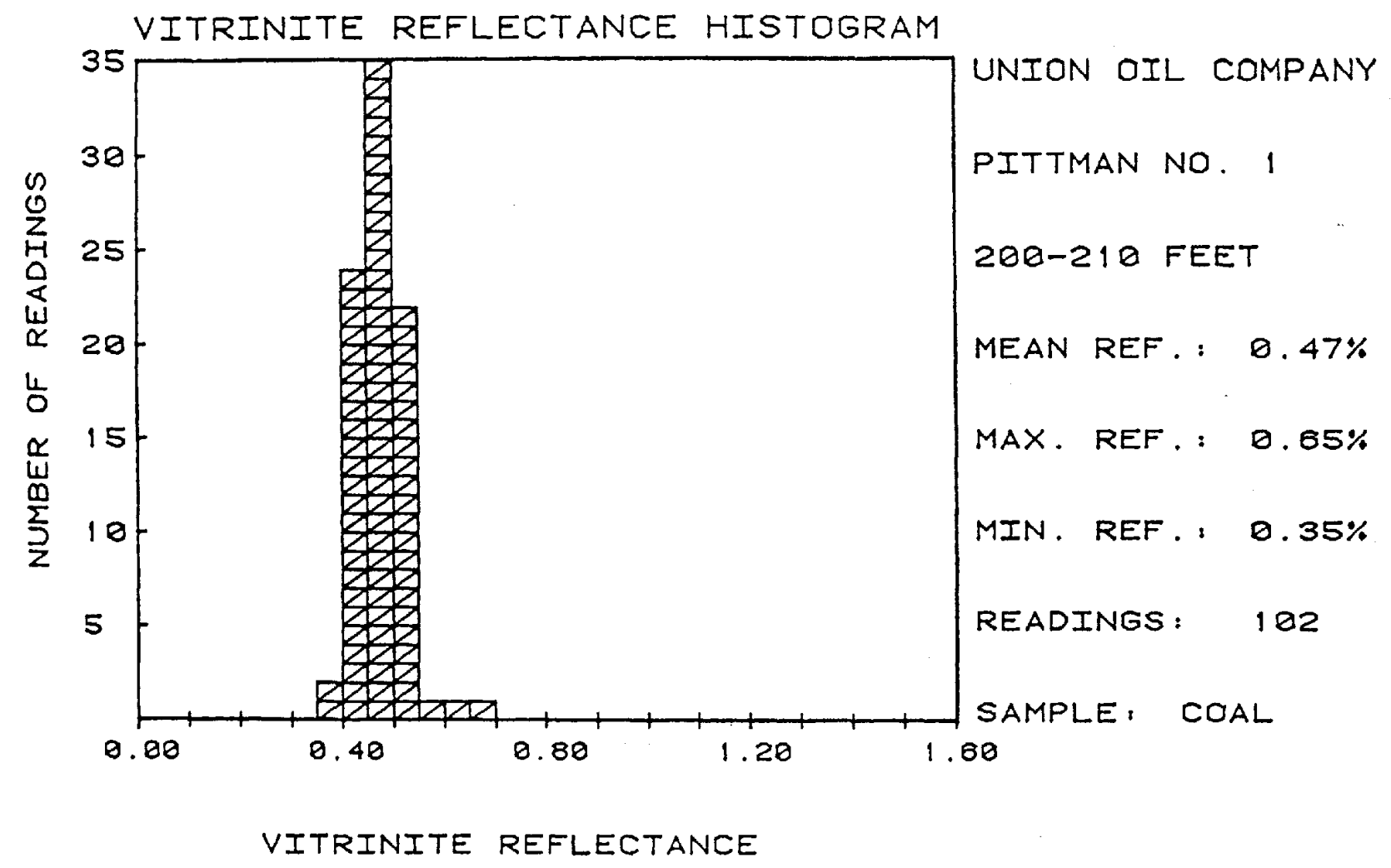

VITRINITE REFLECTANCE DATA

\begin{tabular}{|c|c|c|c|c|c|c|c|c|c|}
\hline Ro $\quad$ Co & Ro & $c t$. & Ro & ct. & Ro & $\mathrm{Ct}$. & Ro & Ro & ct. \\
\hline $\begin{array}{l}0.30 \\
0.36 \\
0.42 \\
0.48 \\
0.54 \\
0.60\end{array}$ & $\begin{array}{l}0.31 \\
0.37 \\
0.43 \\
0.49 \\
0.55 \\
0.61\end{array}$ & $\begin{array}{l}0 \\
0 \\
5 \\
6 \\
0 \\
0\end{array}$ & $\begin{array}{l}0.32 \\
0.38 \\
0.44 \\
0.501 \\
0.56 \\
0.62\end{array}$ & $\begin{array}{r}0 \\
0 \\
12 \\
10 \\
0 \\
1\end{array}$ & $\begin{array}{l}0.33 \\
0.39 \\
0.45 \\
0.51 \\
0.57 \\
0.63\end{array}$ & $\begin{array}{r}0 \\
1 \\
16 \\
3 \\
1 \\
0\end{array}$ & $\begin{array}{l}0.34 \\
0.40 \\
0.461 \\
0.52 \\
0.58 \\
0.64\end{array}$ & $\begin{array}{l}0.35 \\
0.41 \\
0.47 \\
0.53 \\
0.59 \\
0.65\end{array}$ & $\begin{array}{l}1 \\
2 \\
8 \\
4 \\
0 \\
1\end{array}$ \\
\hline
\end{tabular}




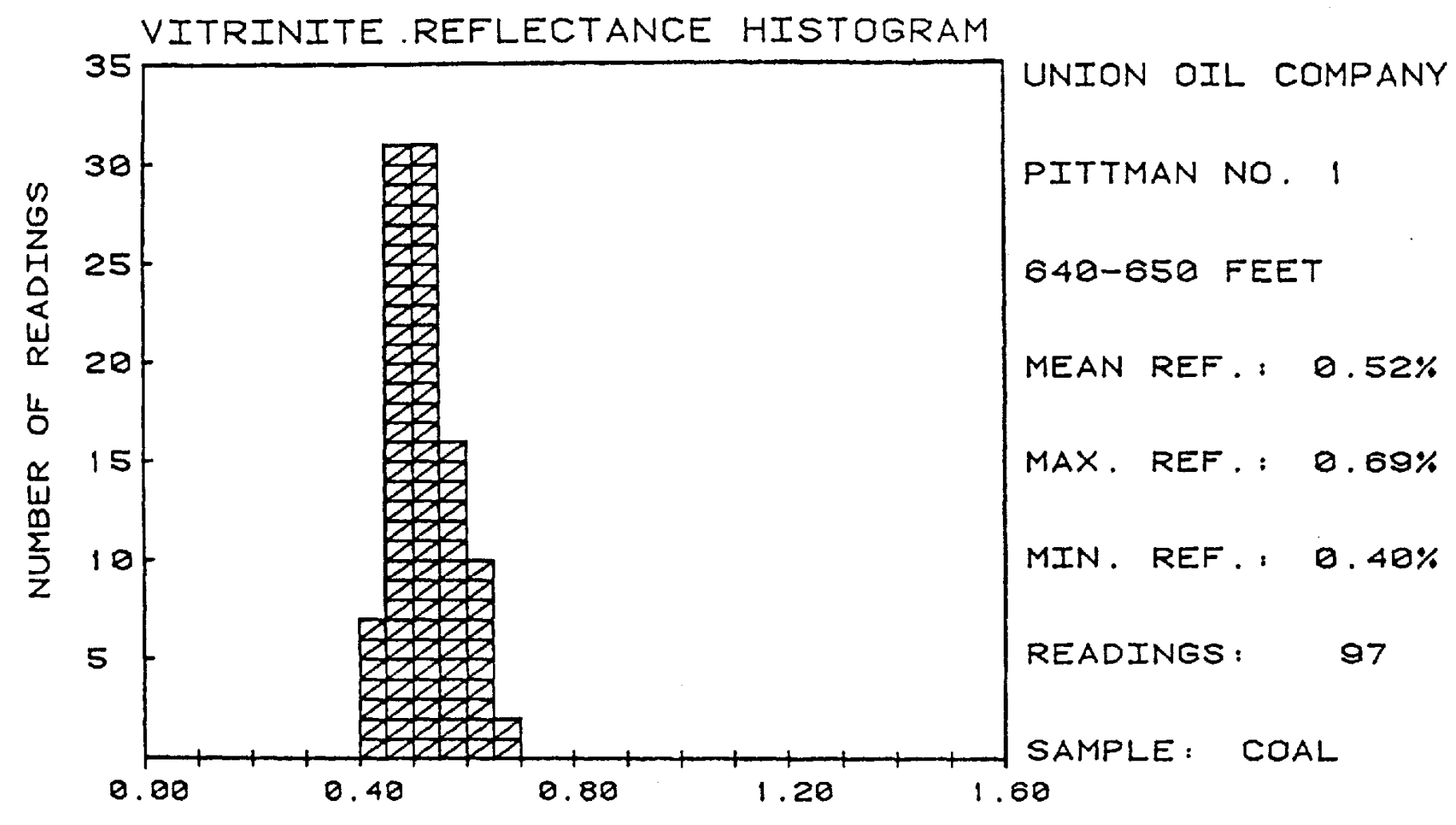

VITRINITE REFLECTANCE

VITRINITE REFLECTANCE DATA
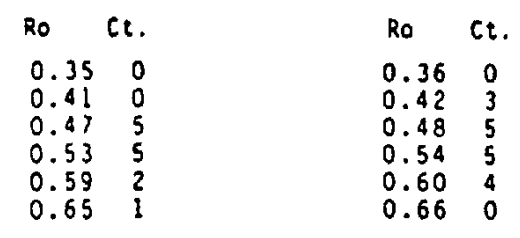

$\begin{array}{ll}80 & \mathrm{Ct} . \\ 0.37 & 0 \\ 0.43 & 1 \\ 0.49 & 6 \\ 0.55 & 4 \\ 0.61 & 2 \\ 0.67 & 0\end{array}$

$\begin{array}{ll}\text { Ro } & \text { Ct. } \\ 0.38 & 0 \\ 0.44 & 2 \\ 0.50 & 7 \\ 0.56 & 6 \\ 0.62 & 1 \\ 0.68 & 0\end{array}$

$\begin{array}{lr}\text { Ro } & \text { Ct. } \\ 0.39 & 0 \\ 0.45 & 10 \\ 0.51 & 9 \\ 0.57 & 3 \\ 0.63 & 2 \\ 0.69 & 1\end{array}$

$\begin{array}{lr}\text { Ro } & \text { Ct. } \\ 0.40 & 1 \\ 0.46 & 5 \\ 0.52 & 5 \\ 0.58 & 1 \\ 0.64 & 1 \\ 0.00 & 0\end{array}$ 


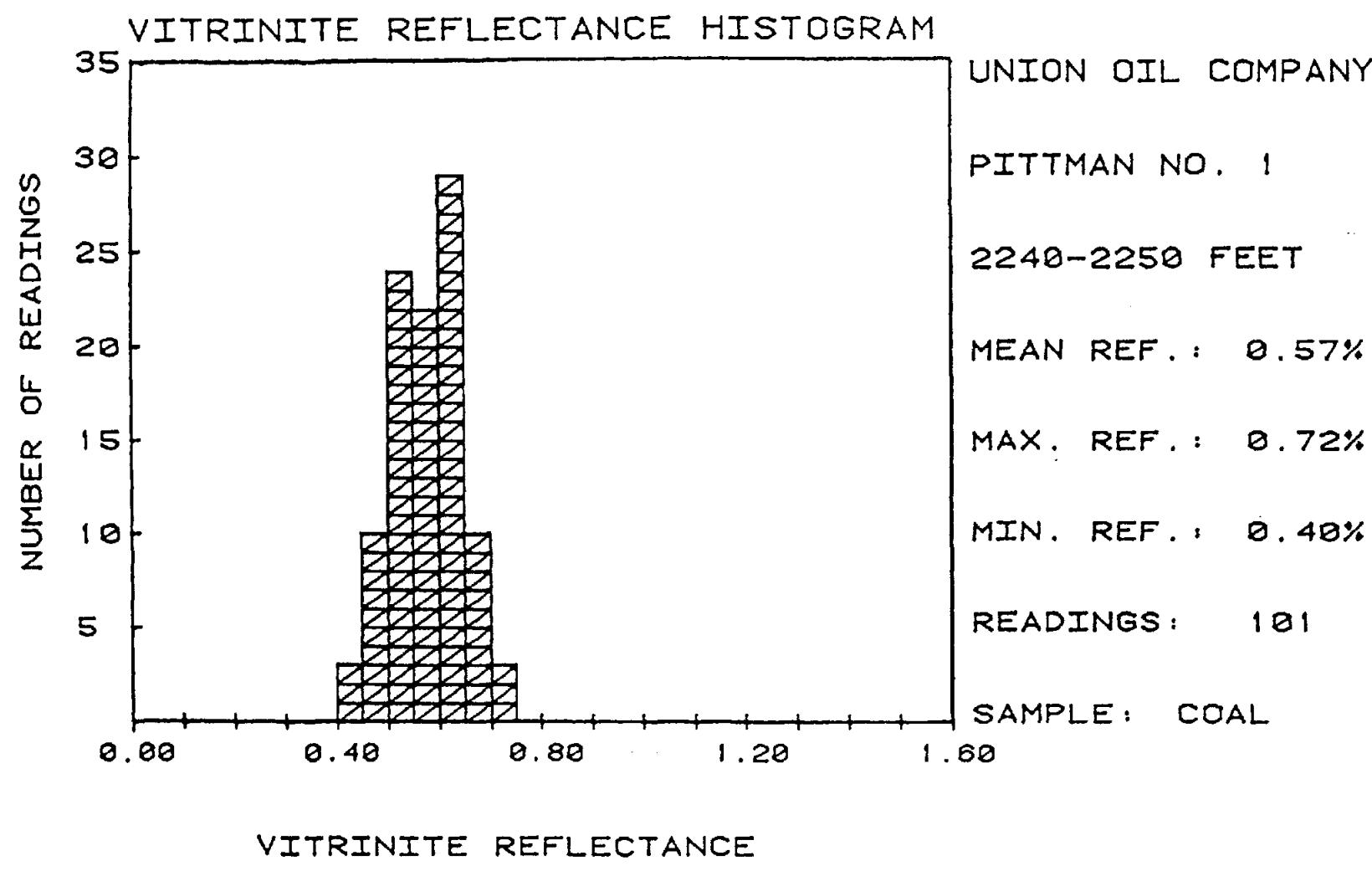

VITRINITE REFLECTANCE DATA
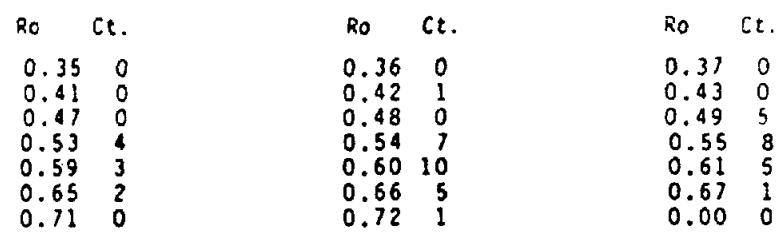

$\begin{array}{lll} & \text { Ro } & \text { Ct. } \\ 38 & 0.38 & 0 \\ 44 & 0.44 & 1 \\ 50 & 0.50 & 6 \\ 56 & 0.56 & 2 \\ 62 & 0.62 & 5 \\ 68 & 0.68 & 2 \\ 74 & 0.00 & 0\end{array}$

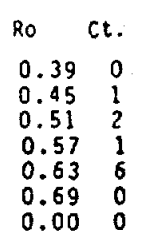

$\begin{array}{ll}\text { Ro } C t . \\ 0.40 & 1 \\ 0.46 & 4 \\ 0.52 & 5 \\ 0.58 & 8 \\ 0.54 & 3 \\ 0.70 & 2 \\ 0.00 & 0\end{array}$ 


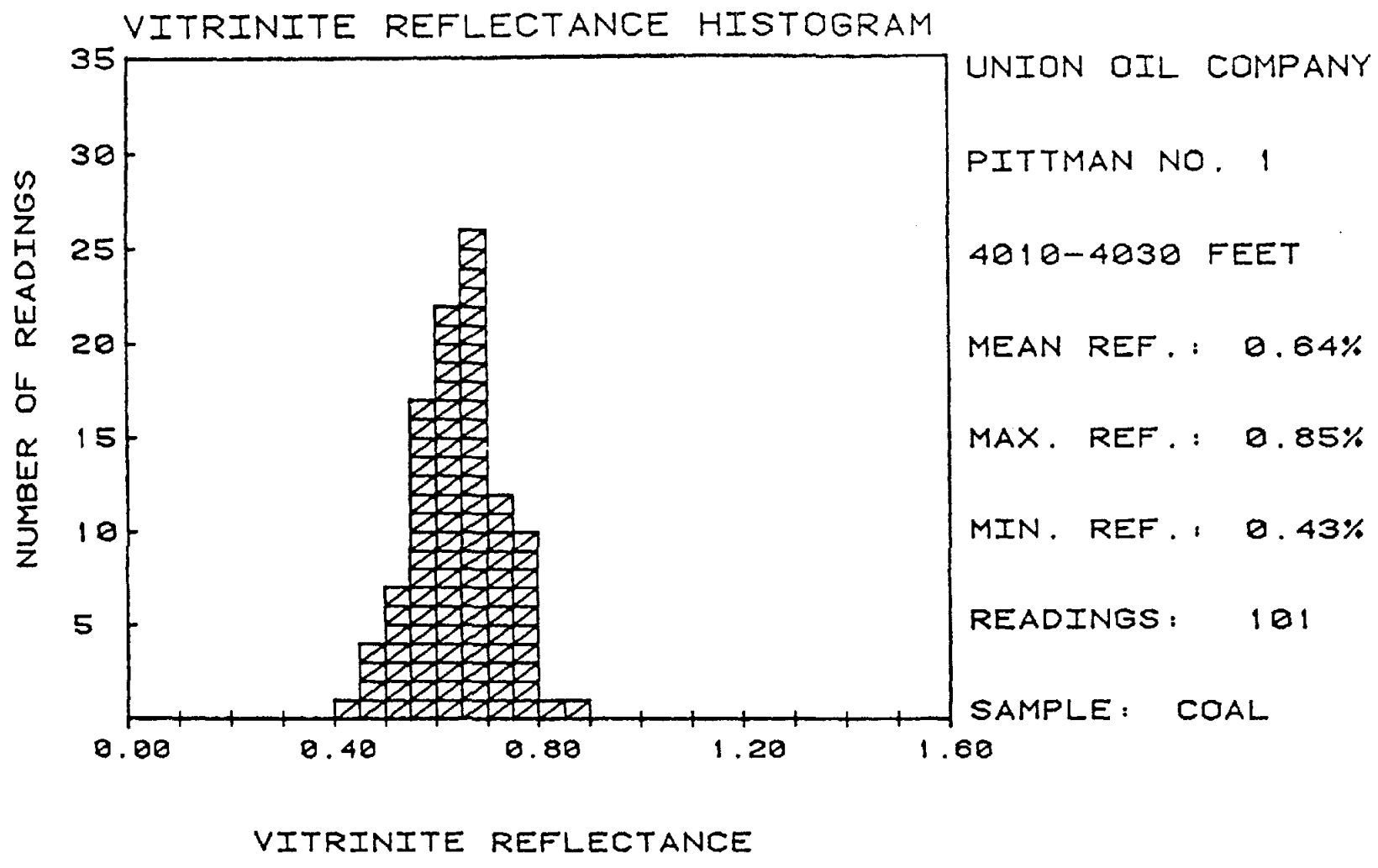

VITRINITE REFLECTANCE D.ATA
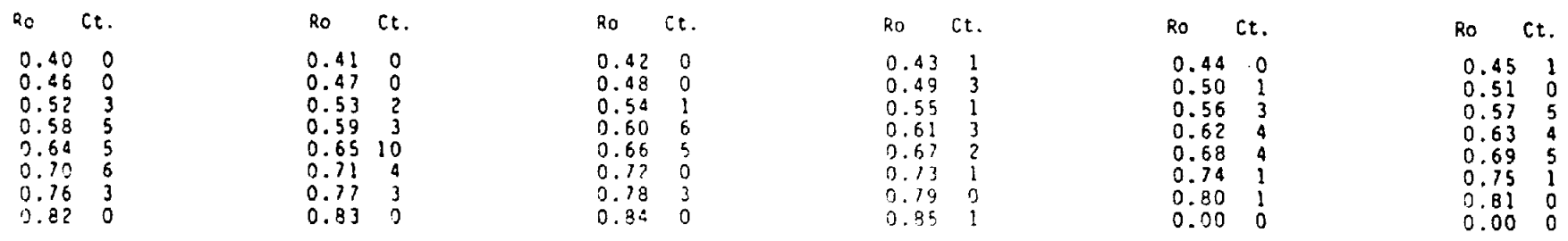


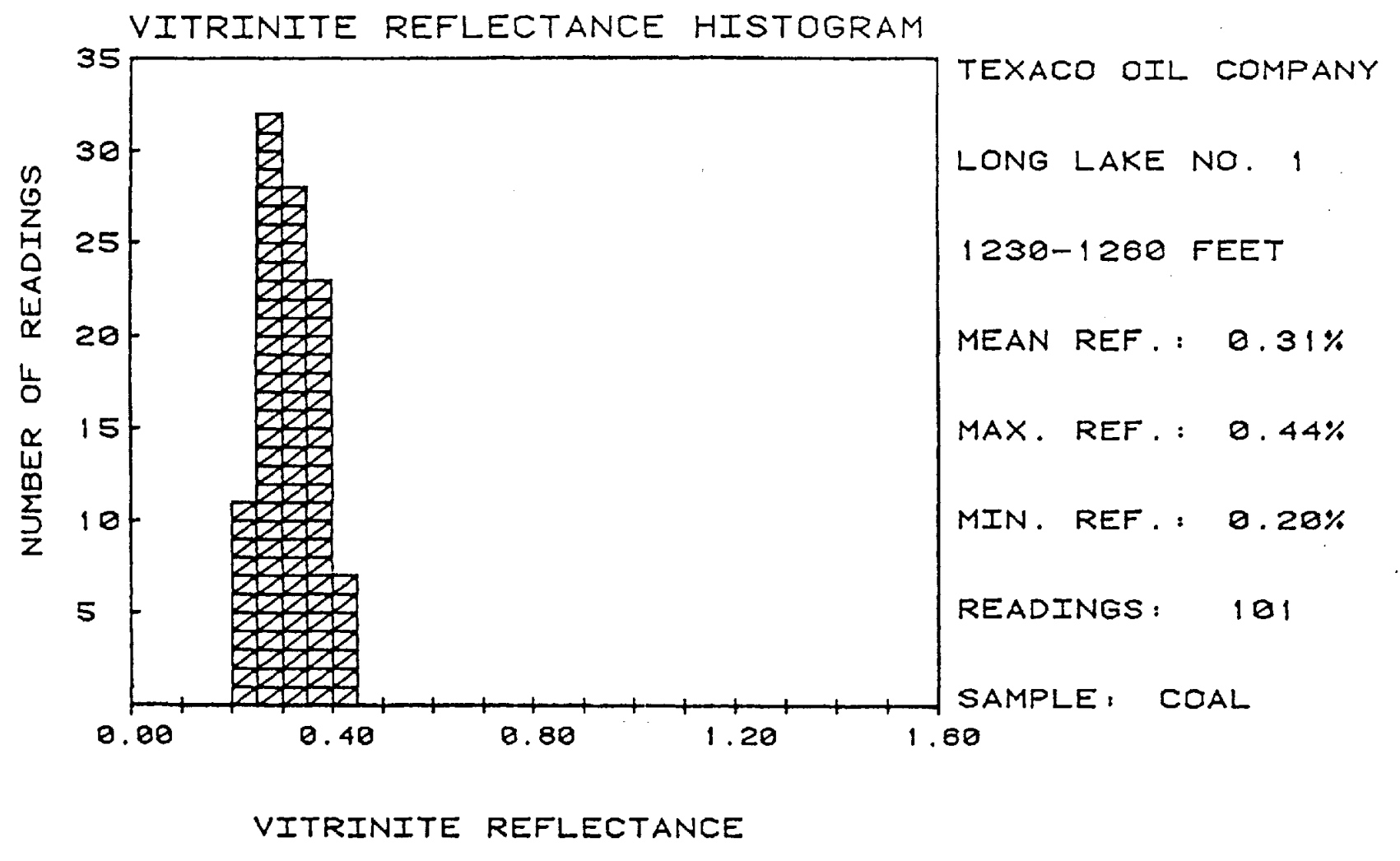

VITRINITE REFLECTANCE DATA
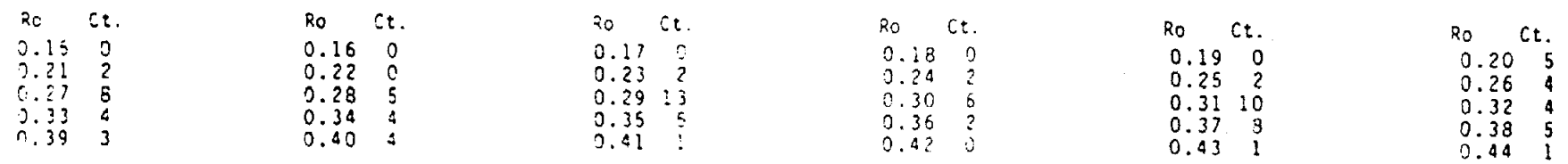


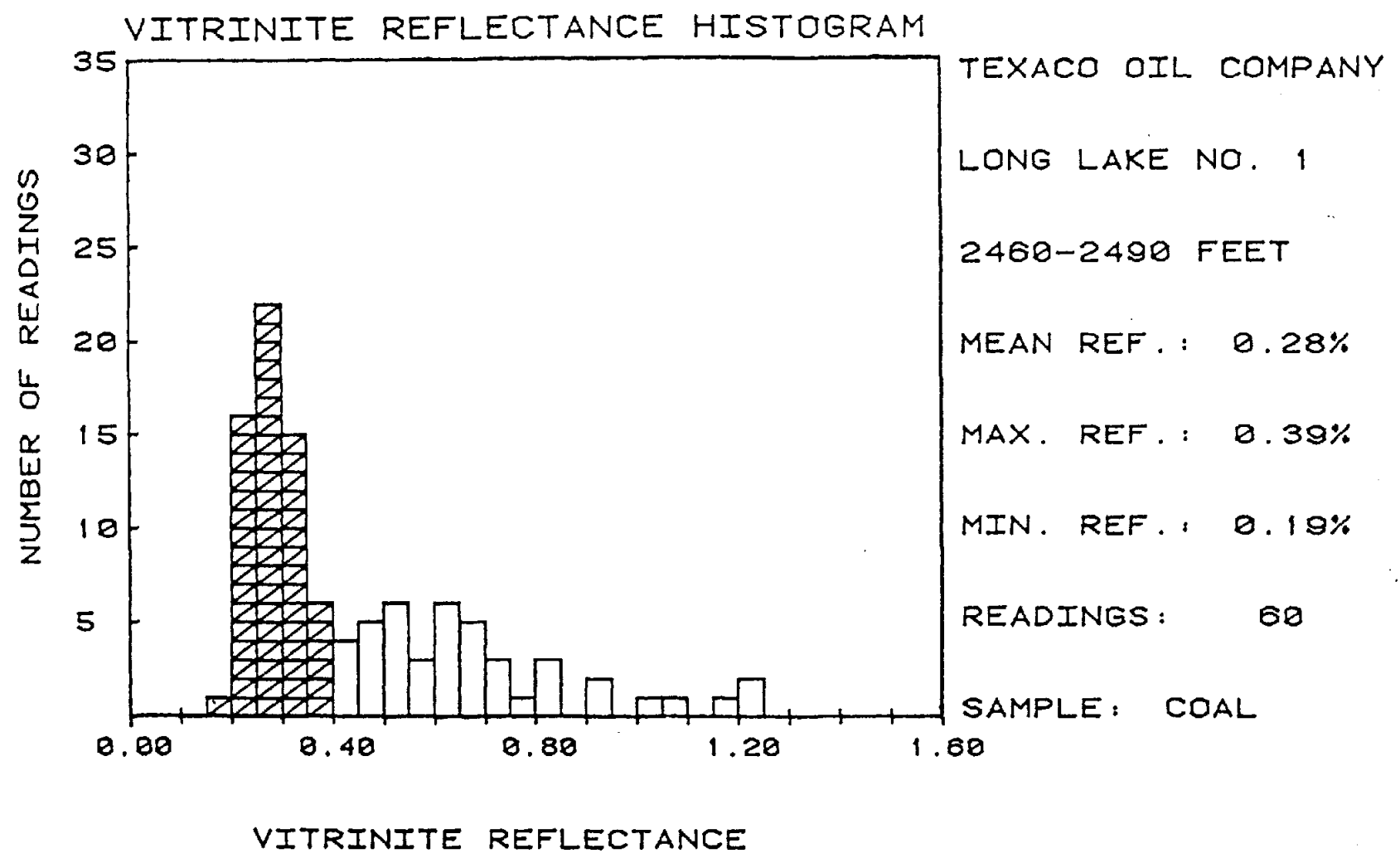

VITRINITE REFLECTANCE DATA
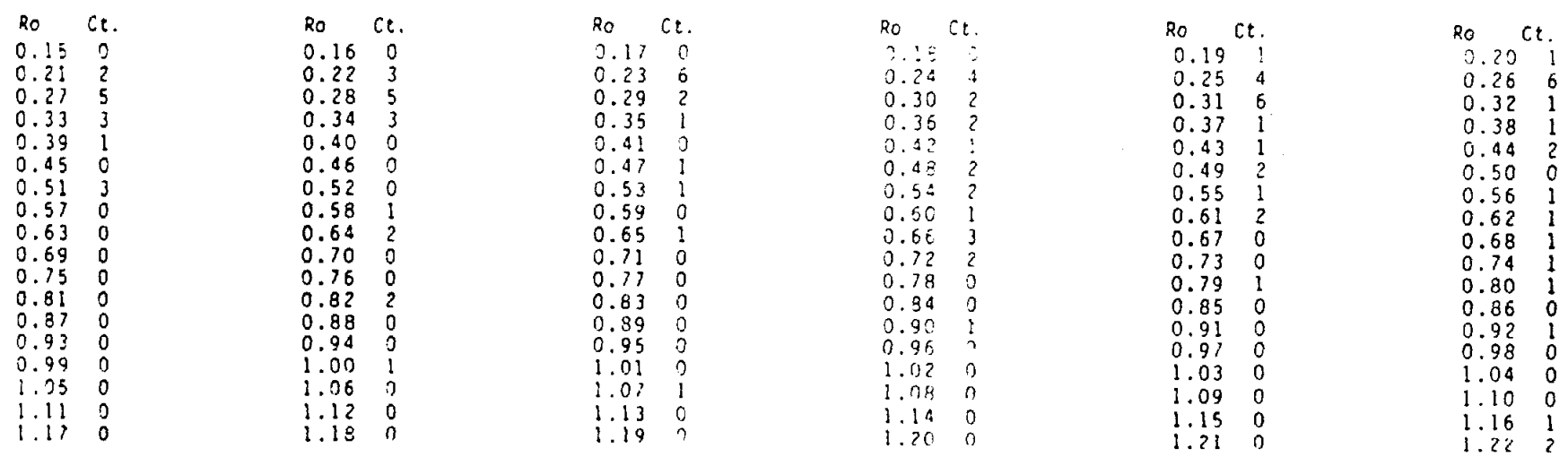


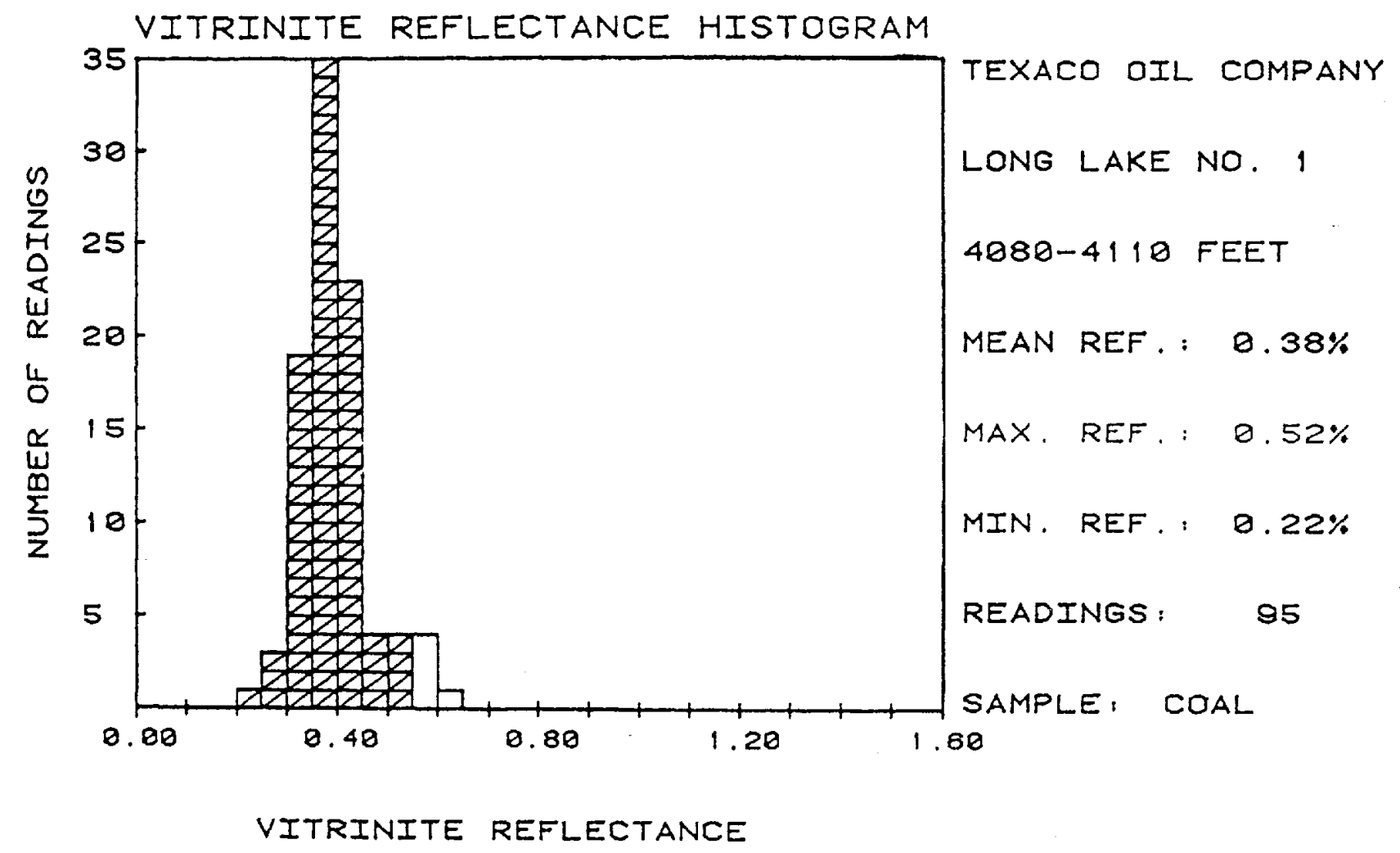

VITRINITE REFLECTANCE DATA
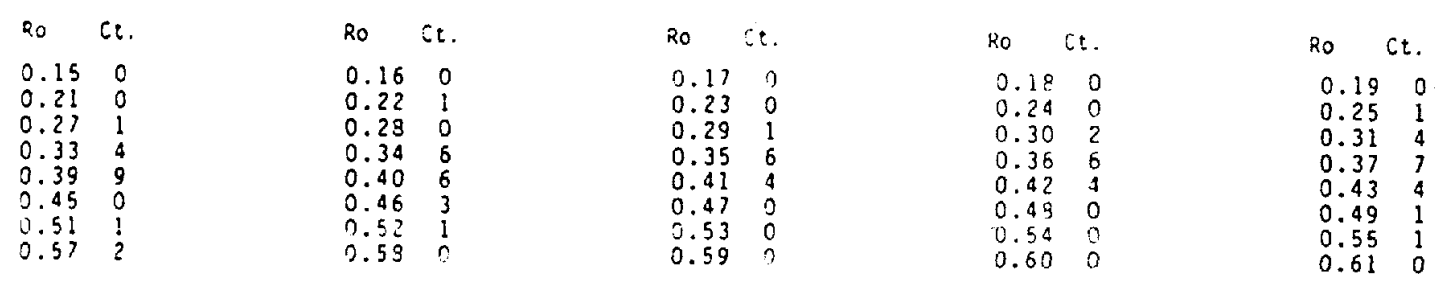

$\begin{array}{lr}\text { Ro } & \text { Ct. } \\ 0.20 & 0 \\ 0.26 & 0 \\ 0.32 & 3 \\ 0.38 & 13 \\ 0.44 & 5 \\ 0.50 & 2 \\ 0.56 & 1 \\ 0.62 & 1\end{array}$ 


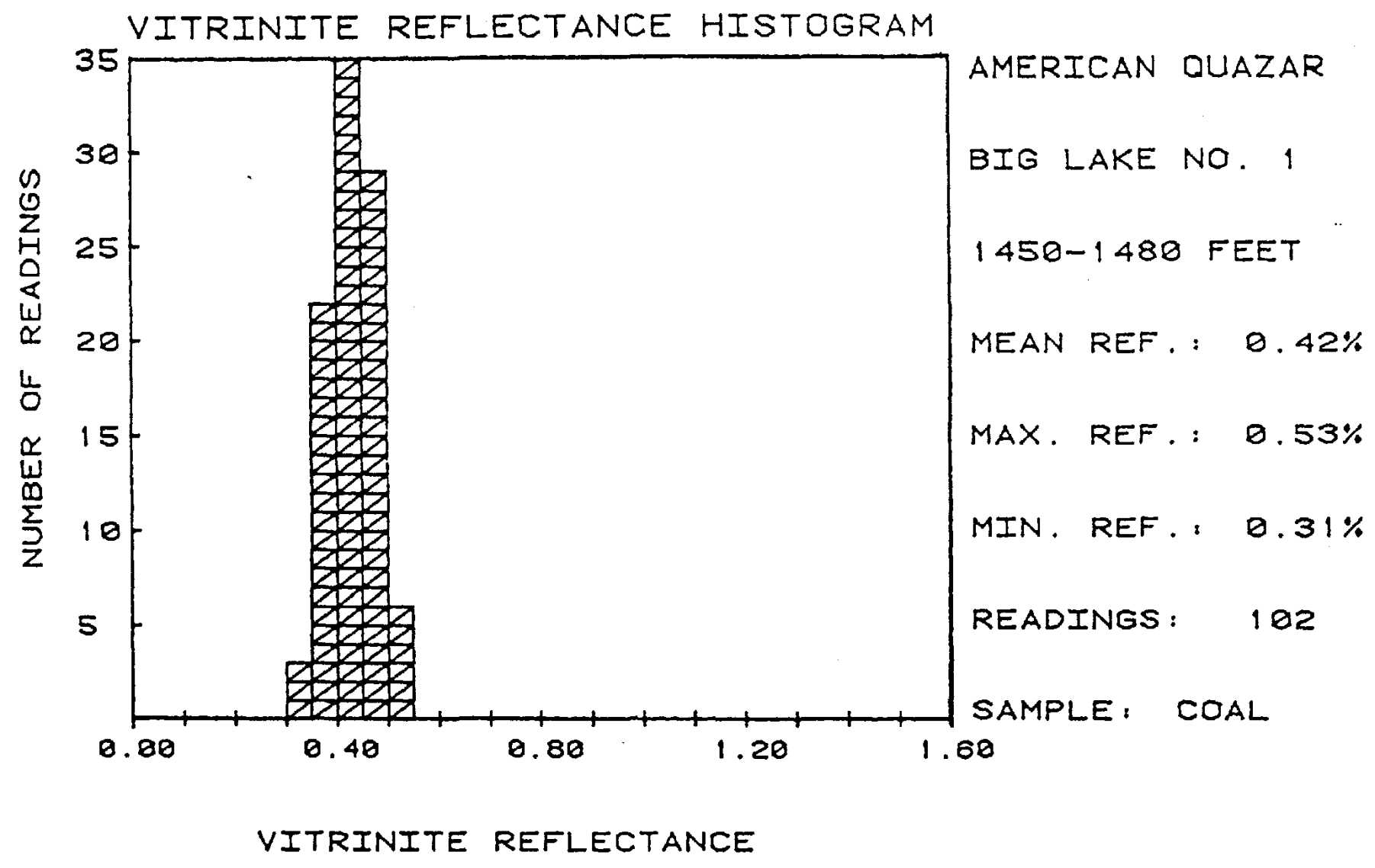

VITRINITE REFLECTANCE DATA
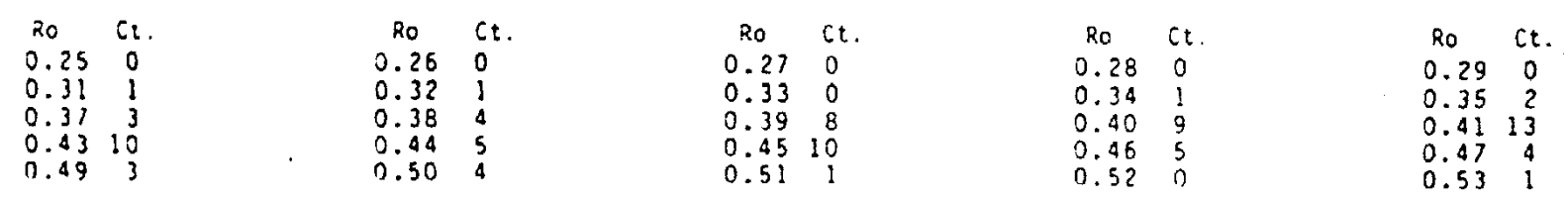

$\begin{array}{ll}\text { Ro } & \text { Ct. } \\ 0.30 & 0 \\ 0.36 & 5 \\ 0.42 & 5 \\ 0.48 & 7 \\ 0.00 & 0\end{array}$ 
WAL Batch: \#8423-110-06

Report of Analysis on Sample: Vobil - Salmonberry Lake \#1 180 - 190 ft REFLECTANCE ANALYSIS

Mean-Maximum Vitrinite Rc: 0.52

Distribution of Vitrintte Reflectance Readings:

\%Ro

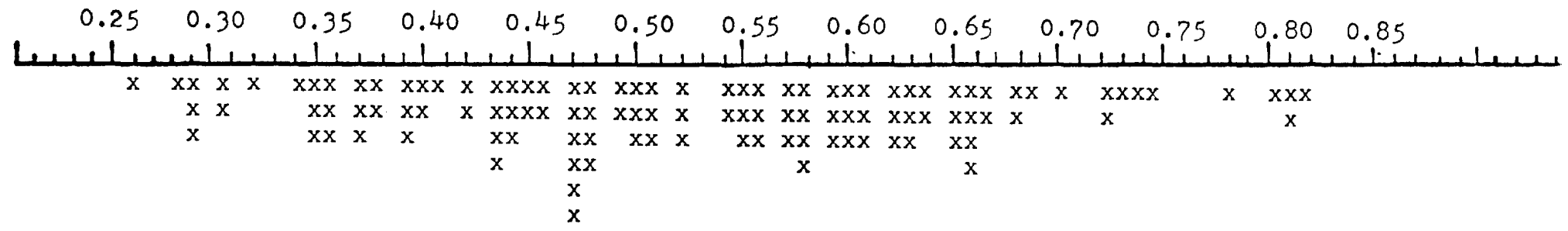

Number of

Counts

(Tota) =

115)

V-Type Table for Vitrinites $(=100 \%)$

$\frac{v-2}{1.7} \quad \frac{v-3}{18.3} \quad \frac{v-4}{24.3} \quad \frac{v-5}{23.5} \quad \frac{v-6}{22.6} \quad \frac{v-7}{6.1} \quad \frac{v-8}{3.5}$ 


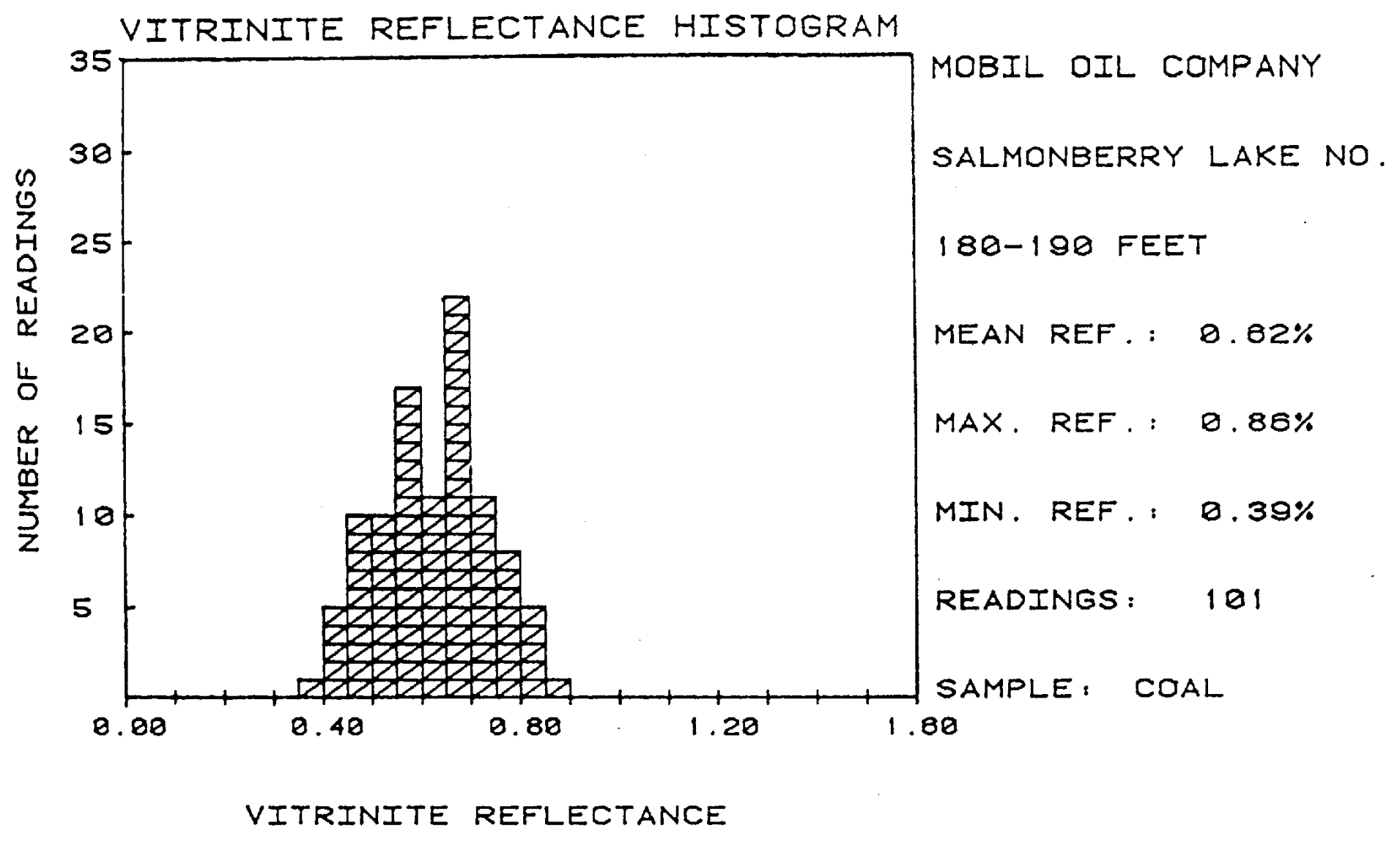

VITRINITE REFLECTANCE DATA
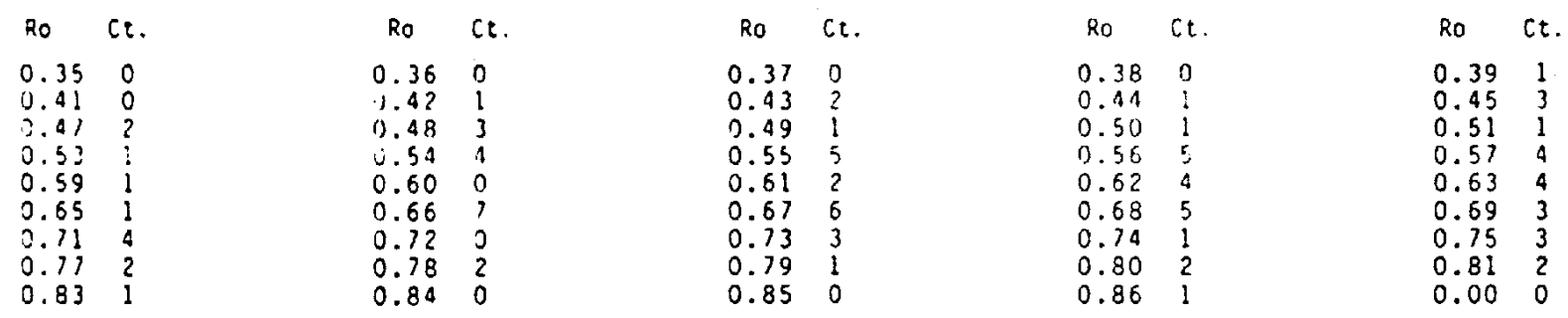

$\begin{array}{lc}\text { Ro } & \text { Ct. } \\ 0.40 & 1 \\ 0.46 & 1 \\ 0.52 & 3 \\ 0.58 & 2 \\ 0.64 & 1 \\ 0.70 & 3 \\ 0.76 & 0 \\ 0.82 & 0 \\ 0.00 & 0\end{array}$ 
WAL Batch: 8423-110-06

Report of Analysis on Sample: Mobil Salmonberry Lake \#1 550 - $560 \mathrm{ft}$.

Mean-Maximum Vitrinite P.o: 0.25

Distribution of Vitrinite Reflectance Readings:

\&Ro

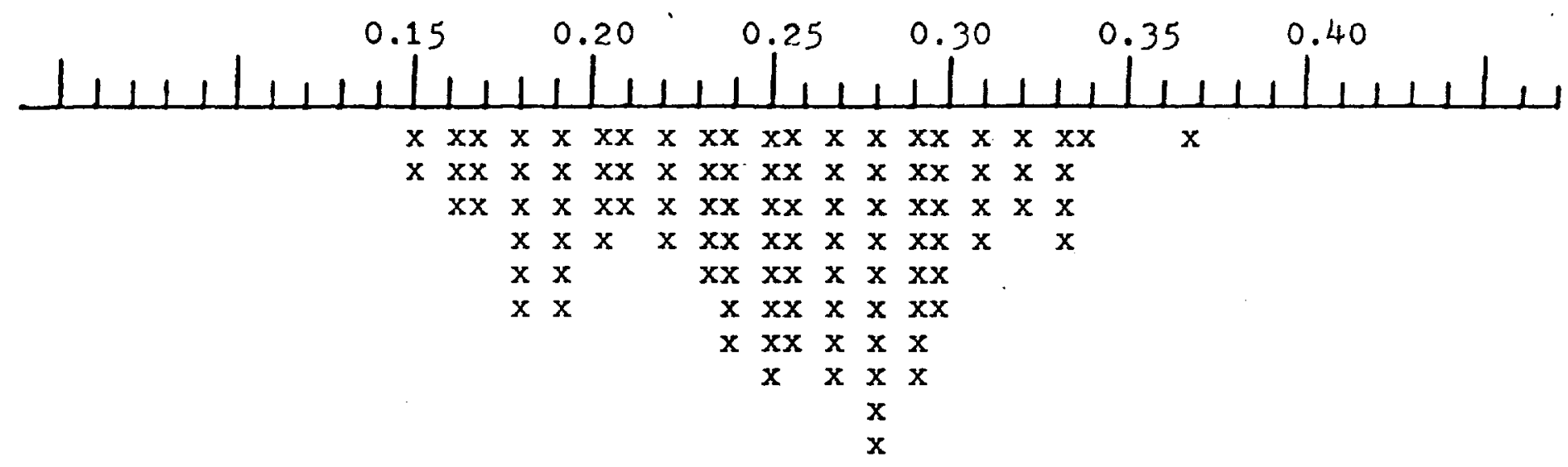

Number of

Counts

$($ Total $=104)$

y-Type Table for Vitrinites $(=100 \%)$

$\frac{v-1}{19.2} \frac{v-2}{62.5} \frac{v-3}{18.3} \quad \underline{v-}$ 


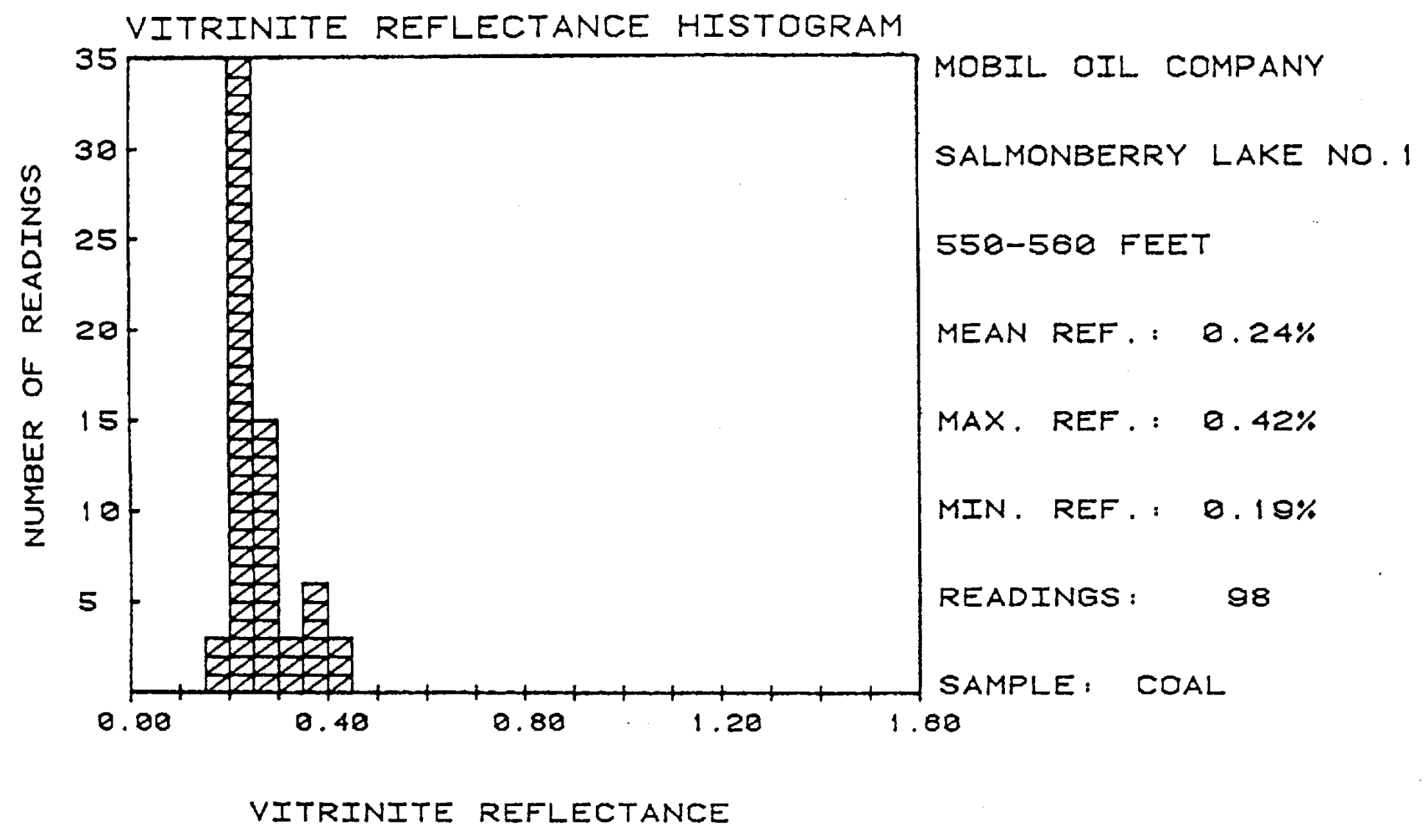

VITRINITE REFLECTANCE UATA
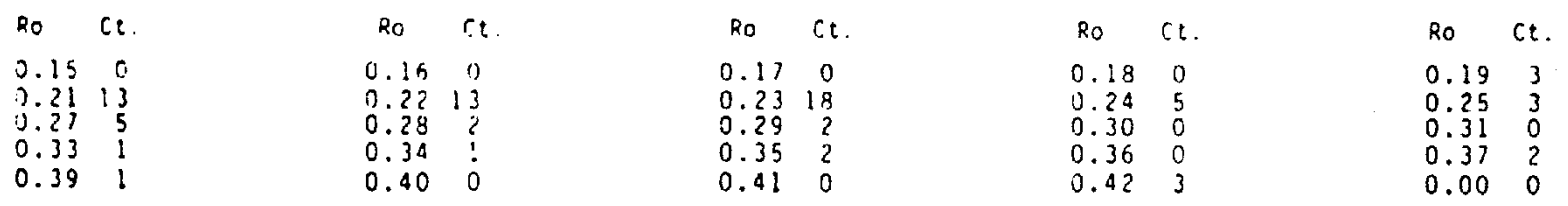

$\begin{array}{lr}\text { Ro } & \text { ct. } \\ 0.20 & 19 \\ 0.26 & 3 \\ 0.32 & 1 \\ 0.38 & 1 \\ 0.00 & 0\end{array}$ 


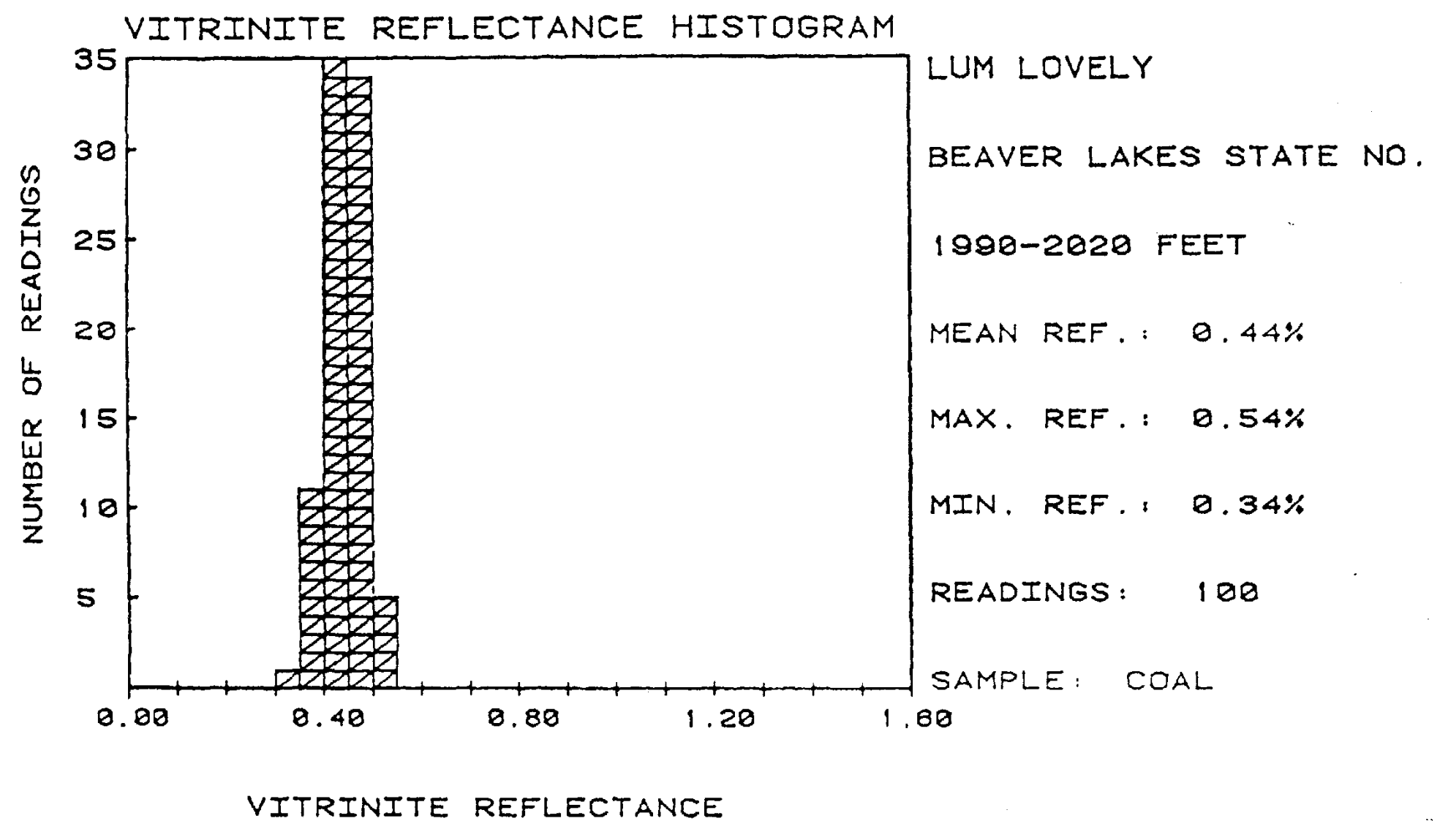

VITRINITE REFLECTANCE DATA

\begin{tabular}{|c|c|c|c|c|c|c|c|c|c|c|c|c|}
\hline Ro & Ce. & Ro & $\mathrm{Cl}$. & & Ro & Cl. & Ro & Ct. & $R_{D}$ & ct. & Ro & Ct. \\
\hline $\begin{array}{l}0.30 \\
0.36 \\
0.42 \\
0.48 \\
0.54\end{array}$ & $\begin{array}{r}0 \\
2 \\
10 \\
2 \\
1\end{array}$ & $\begin{array}{l}0.31 \\
0.37 \\
0.43 \\
0.49 \\
0.00\end{array}$ & $\begin{array}{r}0 \\
4 \\
15 \\
6 \\
0\end{array}$ & $\begin{array}{l}32 \\
38 \\
44 \\
50 \\
56\end{array}$ & $\begin{array}{l}0.32 \\
0.38 \\
0.44 \\
0.50 \\
0.00\end{array}$ & $\begin{array}{r}0 \\
3 \\
13 \\
1 \\
0\end{array}$ & $\begin{array}{l}0.33 \\
0.39 \\
0.45 \\
0.51 \\
0.00\end{array}$ & $\begin{array}{r}0 \\
2 \\
11 \\
1 \\
0\end{array}$ & $\begin{array}{l}0.34 \\
0.40 \\
0.46 \\
0.52 \\
0.00\end{array}$ & $\begin{array}{l}1 \\
5 \\
9 \\
2 \\
0\end{array}$ & $\begin{array}{l}0.35 \\
0.41 \\
0.47 \\
0.53 \\
0.00\end{array}$ & $\begin{array}{l}0 \\
5 \\
5 \\
0 \\
0\end{array}$ \\
\hline
\end{tabular}




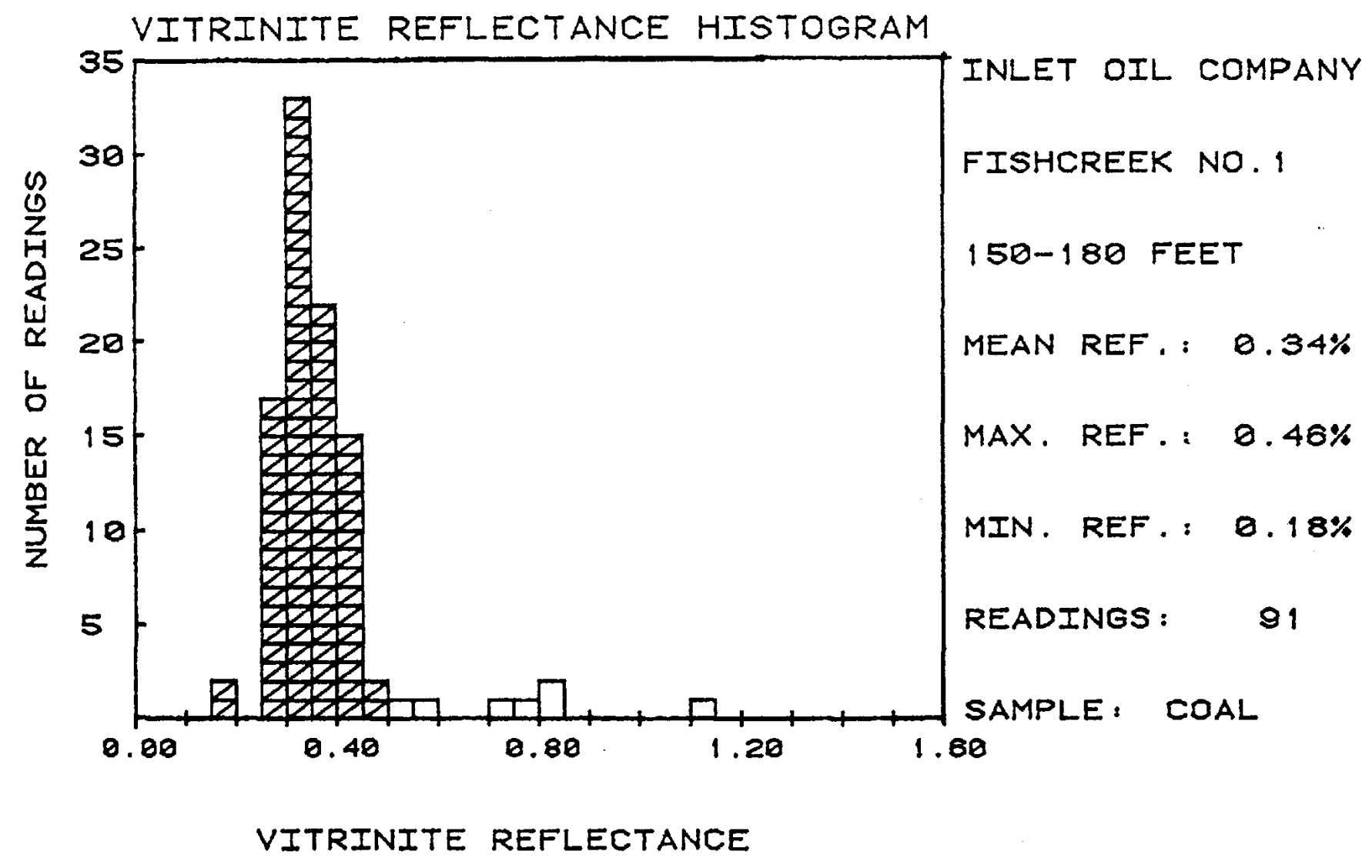

VITRINITE REFLECTANCE DATA

$\begin{array}{ll}\text { Ro } & C t \\ 0.10 & 0 \\ 0.16 & 0 \\ 0.22 & 0 \\ 0.28 & 4 \\ 0.34 & 8 \\ 0.40 & 7 \\ 0.46 & 1 \\ 0.52 & 0 \\ 0.58 & 0 \\ 0.64 & 0 \\ 0.70 & 0 \\ 0.76 & 0 \\ 0.82 & 1 \\ 0.88 & 0 \\ 0.94 & 0 \\ 1.00 & 0 \\ 1.06 & 0\end{array}$

$\begin{array}{ll}\text { Ro } & \text { Ct. } \\ 0.11 & 0 \\ 0.17 & 0 \\ 0.23 & 0 \\ 0.29 & 6 \\ 0.35 & 5 \\ 0.41 & 3 \\ 0.47 & 0 \\ 0.53 & 0 \\ 0.59 & 0 \\ 0.65 & 0 \\ 0.71 & 0 \\ 0.77 & 1 \\ 0.83 & 1 \\ 0.89 & 0 \\ 0.95 & 0 \\ 1.01 & 0 \\ 1.07 & 0\end{array}$

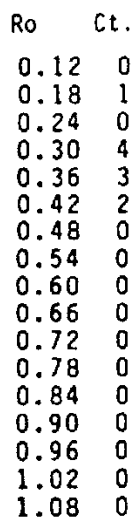

$\begin{array}{ll}\text { Ro } & C t . \\ 0.13 & 0 \\ 0.19 & 1 \\ 0.25 & 4 \\ 0.31 & 6 \\ 0.37 & 6 \\ 0.43 & 2 \\ 0.49 & 0 \\ 0.55 & 0 \\ 0.61 & 0 \\ 0.67 & 0 \\ 0.73 & 1 \\ 0.79 & 0 \\ 0.85 & 0 \\ 0.91 & 0 \\ 0.97 & 0 \\ 1.03 & 0 \\ 1.09 & 0\end{array}$

$\begin{array}{ll}\text { Ro } & C t . \\ 0.14 & 0 \\ 0.20 & 0 \\ 0.26 & 0 \\ 0.32 & 4 \\ 0.38 & 3 \\ 0.44 & 1 \\ 0.50 & 0 \\ 0.56 & 0 \\ 0.62 & 0 \\ 0.68 & 0 \\ 0.74 & 0 \\ 0.80 & 0 \\ 0.86 & 0 \\ 0.92 & 0 \\ 0.98 & 0 \\ 1.04 & 0 \\ 1.10 & 0\end{array}$

Ro Ct.

0.150

0.210

0.273

0.3311

0.395

0.451

0.511

0.531

0.630

$0.75 \quad 0$

0.810

0.870

0.930

0.990

$1.05 \quad 0$ 


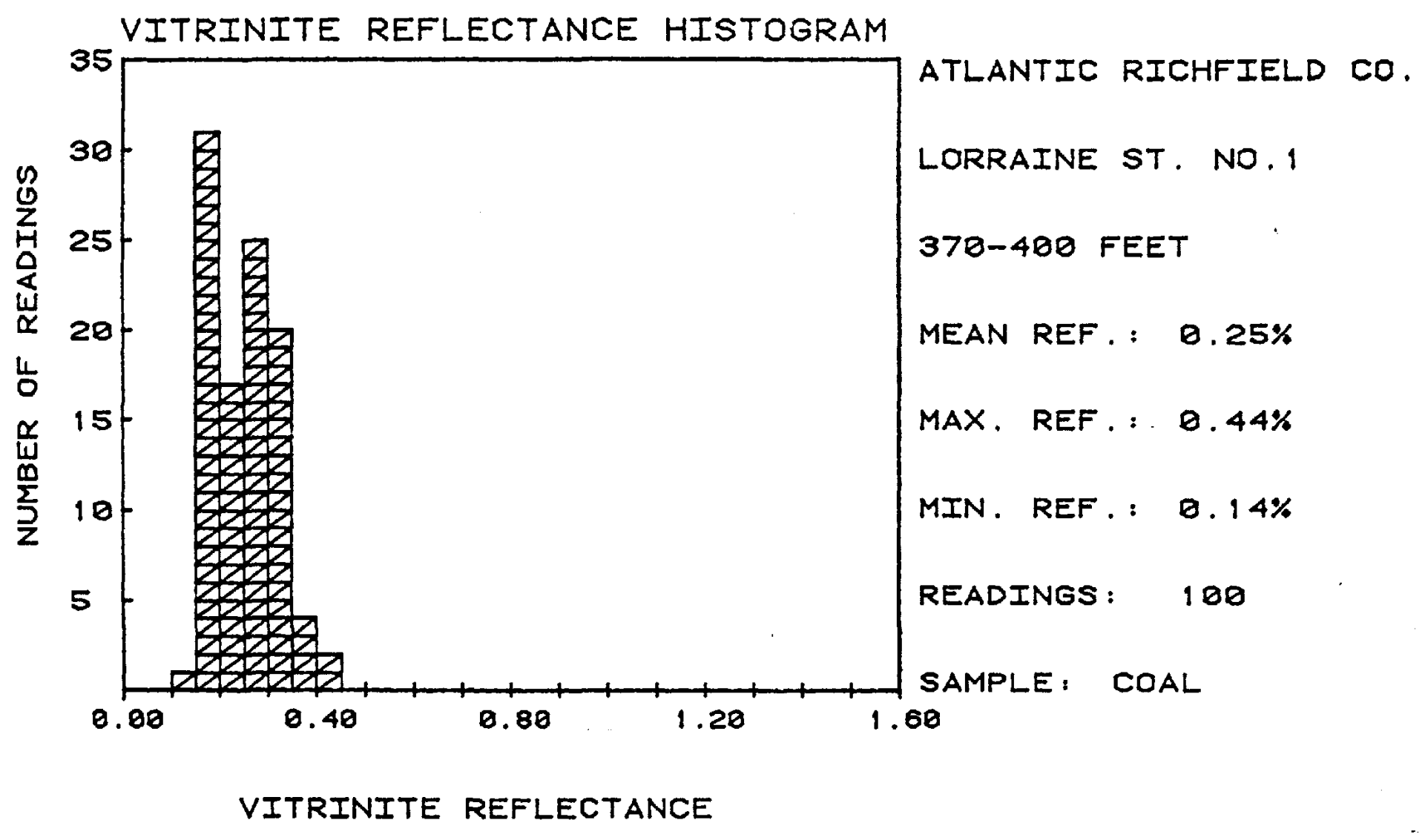

VITRINITE REFLECTANCE DATA

Ro Ct.

0.100

0.168

0.221

$0.28 \quad 4$

0.342

0.401
Ro Ct.

$\begin{array}{ll}0.11 & 0 \\ 0.17 & 8 \\ 0.23 & 6 \\ 0.29 & 3 \\ 0.35 & 1 \\ 0.41 & 0\end{array}$
Ro Ct.

$\begin{array}{ll}0.12 & 0 \\ 0.18 & 5 \\ 0.24 & 5 \\ 0.30 & 5 \\ 0.36 & 1 \\ 0.42 & 0\end{array}$
Ro $\mathrm{Ct}$.

0.130

$\begin{array}{ll}0.19 & 8 \\ 0.25 & 7\end{array}$

0.311

0.371 $\begin{array}{ll}\text { Ro } & C t . \\ & \\ 0.14 & 1 \\ 0.20 & 4 \\ 0.26 & 2 \\ 0.32 & 1 \\ 0.38 & 1 \\ 0.44 & 0\end{array}$

Ro $C t$.

0.152

0.211

0.279

0.331

0.390 


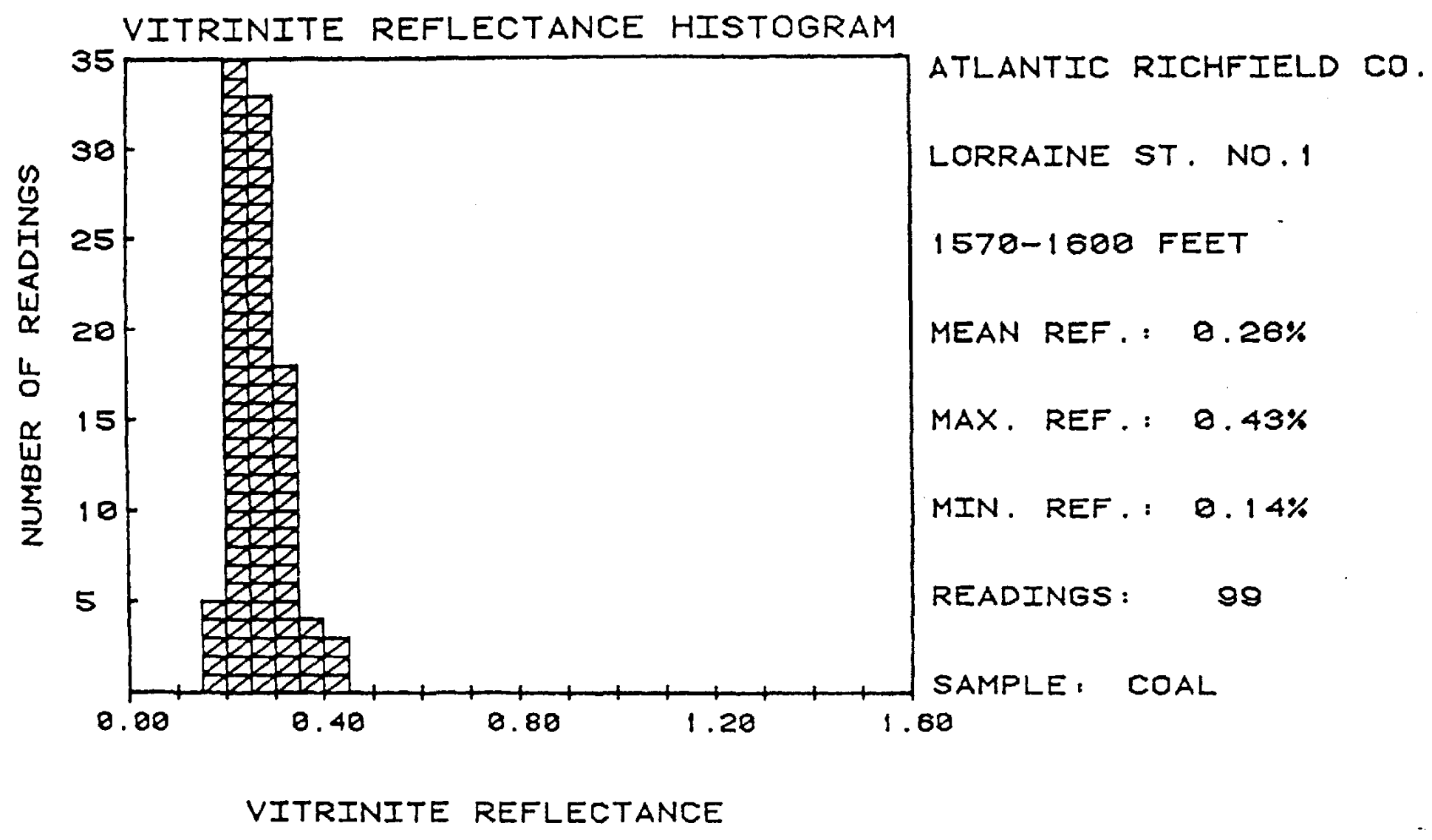

VITRINITE REFLECTANCE DATA

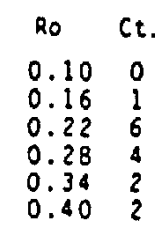

Ro Ct.

0.110

0.111

0.239

$\begin{array}{ll}0.29 & 5 \\ 0.35 & 2\end{array}$

$\begin{array}{ll}0.35 & 2 \\ 0.41 & 0\end{array}$

$\begin{array}{lc}\text { Ro } & C t . \\ 0.12 & 0 \\ 0.18 & 0 \\ 0.24 & 9 \\ 0.30 & 7 \\ 0.36 & 2 \\ 0.42 & 0\end{array}$

Ro $C t$

$\begin{array}{ll}0.13 & 0 \\ 0.19 & 2\end{array}$

$\begin{array}{ll}0.19 & 2 \\ 0.25 & 7\end{array}$

0.312

$\begin{array}{ll}0.37 & 0 \\ 0.43 & 1\end{array}$

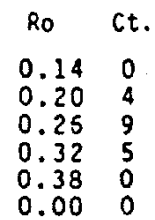

$\begin{array}{ll}\text { Ro } & C t . \\ 0.15 & 1 \\ 0.21 & 8 \\ 0.27 & 8 \\ 0.33 & 2 \\ 0.39 & 0 \\ 0.00 & 0\end{array}$ 


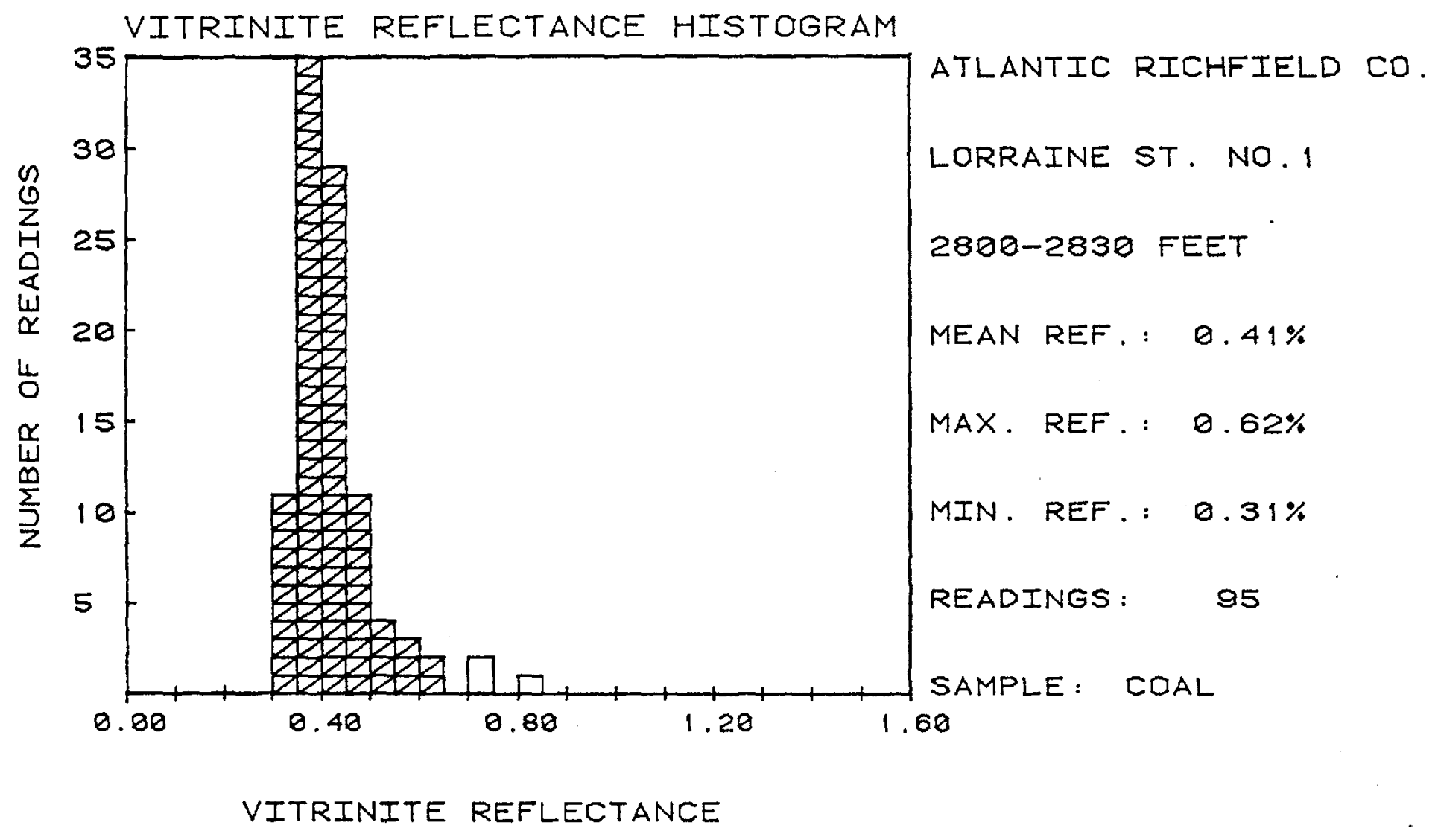

VITRINITE REFLECTANCE DATA

$\begin{array}{ll}\text { Ro } & c t . \\ 0.25 & 0 \\ 0.31 & 1 \\ 0.37 & 8 \\ 0.43 & 5 \\ 0.49 & 2 \\ 0.55 & 1 \\ 0.61 & 0 \\ 0.67 & 0 \\ 0.73 & 1 \\ 0.79 & 0 \\ 0.85 & 0 \\ 0.91 & 0 \\ 0.97 & 0\end{array}$
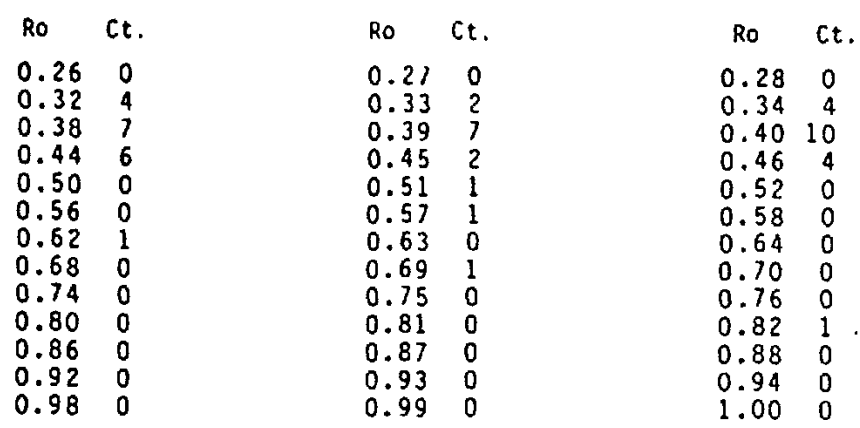

$\begin{array}{ll}\text { Ro } & C t . \\ 0.29 & 0 \\ 0.35 & 3 \\ 0.41 & 1 \\ 0.47 & 0 \\ 0.53 & 2 \\ 0.59 & 1 \\ 0.65 & 0 \\ 0.71 & 0 \\ 0.77 & 0 \\ 0.83 & 0 \\ 0.89 & 0 \\ 0.95 & 0 \\ 1.01 & 0\end{array}$

$\begin{array}{lr}\text { Ro } & \text { Ct. } \\ 0.30 & 0 \\ 0.36 & 10 \\ 0.42 & 7 \\ 0.48 & 3 \\ 0.54 & 1 \\ 0.60 & 1 \\ 0.66 & 1 \\ 0.72 & 1 \\ 0.78 & 0 \\ 0.84 & 0 \\ 0.90 & 0 \\ 0.96 & 0 \\ 1.02 & 1\end{array}$ 


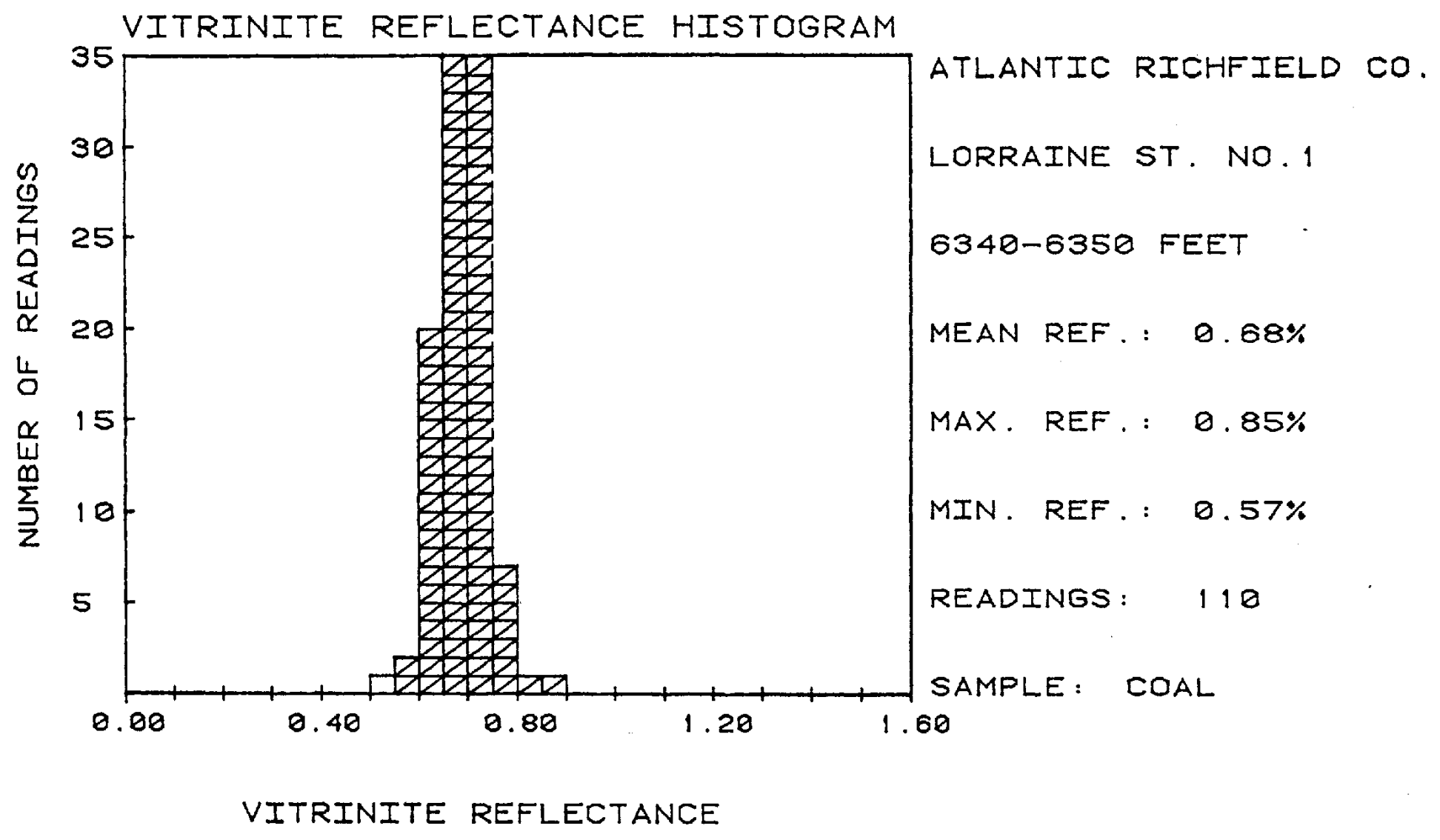

VITRINITE REFLECTANCE DATA

$\begin{array}{lrlll}\text { Ro } & c t . & \text { Ro } & c t . \\ 0.55 & 0 & 0.56 & 0 \\ 0.61 & 4 & 0.62 & 2 \\ 0.67 & 10 & 0.68 & 6 \\ 0.73 & 10 & 0.74 & 2 \\ 0.79 & 2 & 0.80 & 0 \\ 0.85 & 1 & 0.00 & 0\end{array}$

$\begin{array}{cl}\text { Ro } & \text { Ct. } \\ 0.58 & 0 \\ 0.64 & 4 \\ 0.70 & 8 \\ 0.76 & 0 \\ 0.82 & 0 \\ 0.00 & 0\end{array}$

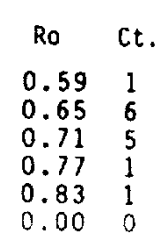

$\begin{array}{lr}\text { Ro } & \text { Ct. } \\ 0.60 & 4 \\ 0.66 & 11 \\ 0.72 & 10 \\ 0.78 & 2 \\ 0.84 & 0 \\ 0.00 & 0\end{array}$ 


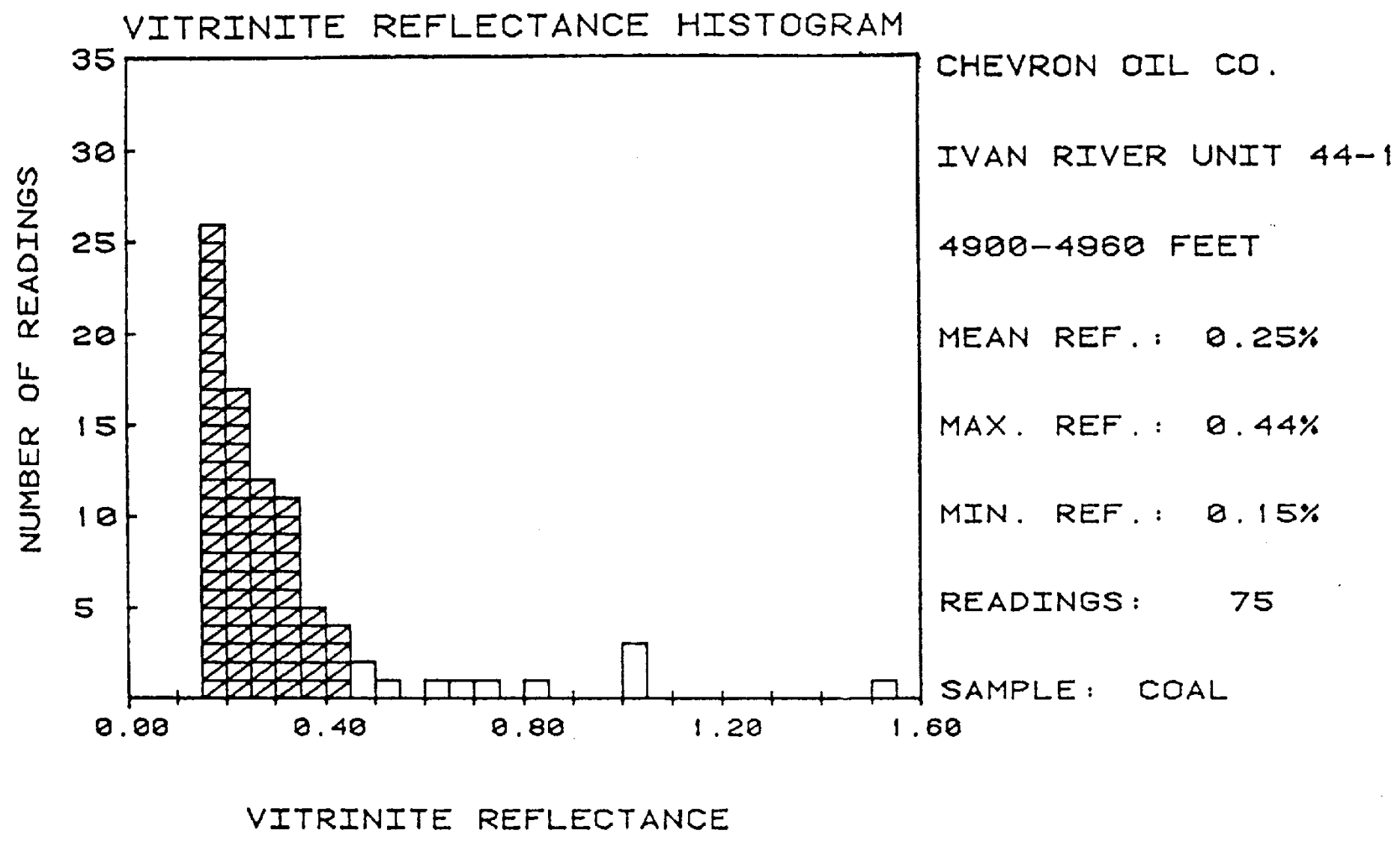

VITRINITE REFLECTANCE DATA

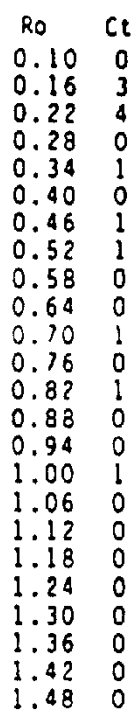

$\begin{array}{ll}R O & C t . \\ 0.11 & 0 \\ 0.17 & 8 \\ 0.23 & 4 \\ 0.29 & 2 \\ 0.35 & 2 \\ 0.41 & 1 \\ 0.47 & 1 \\ 0.53 & 0 \\ 0.59 & 0 \\ 0.65 & 0 \\ 0.71 & 0 \\ 0.17 & 0 \\ 0.83 & 0 \\ 0.89 & 0 \\ 0.95 & 0 \\ 1.01 & 0 \\ 1.07 & 0 \\ 1.13 & 0 \\ 1.19 & 0 \\ 1.25 & 0 \\ 1.31 & 0 \\ 1.37 & 0 \\ 1.43 & 0 \\ 1.49 & 0\end{array}$

$\begin{array}{ll}\text { Ro } & C t . \\ 0.12 & 0 \\ 0.18 & 8 \\ 0.24 & 1 \\ 0.30 & 4 \\ 0.36 & 0 \\ 0.42 & 1 \\ 0.48 & 0 \\ 0.54 & 0 \\ 0.60 & 0 \\ 0.66 & 1 \\ 0.12 & 0 \\ 0.78 & 0 \\ 0.84 & 0 \\ 0.90 & 0 \\ 0.96 & 0 \\ 1.02 & 0 \\ 1.08 & 0 \\ 1.14 & 0 \\ 1.20 & 0 \\ 1.26 & 0 \\ 1.32 & 0 \\ 1.38 & 0 \\ 1.44 & 0 \\ 1.50 & 1\end{array}$

$\begin{array}{ll}R 0 & c t . \\ 0.13 & 0 \\ 0.19 & 5 \\ 0.25 & 1 \\ 0.31 & 2 \\ 0.37 & 1 \\ 0.43 & 1 \\ 0.49 & 0 \\ 0.55 & 0 \\ 0.61 & 1 \\ 0.67 & 0 \\ 0.73 & 0 \\ 0.79 & 0 \\ 0.85 & 0 \\ 0.91 & 0 \\ 0.97 & 0 \\ 1.03 & 1 \\ 1.09 & 0 \\ 1.15 & 0 \\ 1.21 & 0 \\ 1.27 & 0 \\ 1.33 & 0 \\ 1.39 & 0 \\ 1.45 & 0 \\ 0.00 & 0\end{array}$

$\begin{array}{ll}R o & C t . \\ 0.14 & 0 \\ 0.20 & 5 \\ 0.26 & 6 \\ 0.32 & 2 \\ 0.38 & 0 \\ 0.44 & 1 \\ 0.50 & 0 \\ 0.56 & 0 \\ 0.62 & 0 \\ 0.68 & 0 \\ 0.74 & 0 \\ 0.80 & 0 \\ 0.86 & 0 \\ 0.92 & 0 \\ 0.98 & 0 \\ 1.04 & 1 \\ 1.10 & 0 \\ 1.15 & 0 \\ 1.22 & 0 \\ 1.28 & 0 \\ 1.34 & 0 \\ 1.40 & 0 \\ 1.46 & 0 \\ 0.00 & 0\end{array}$




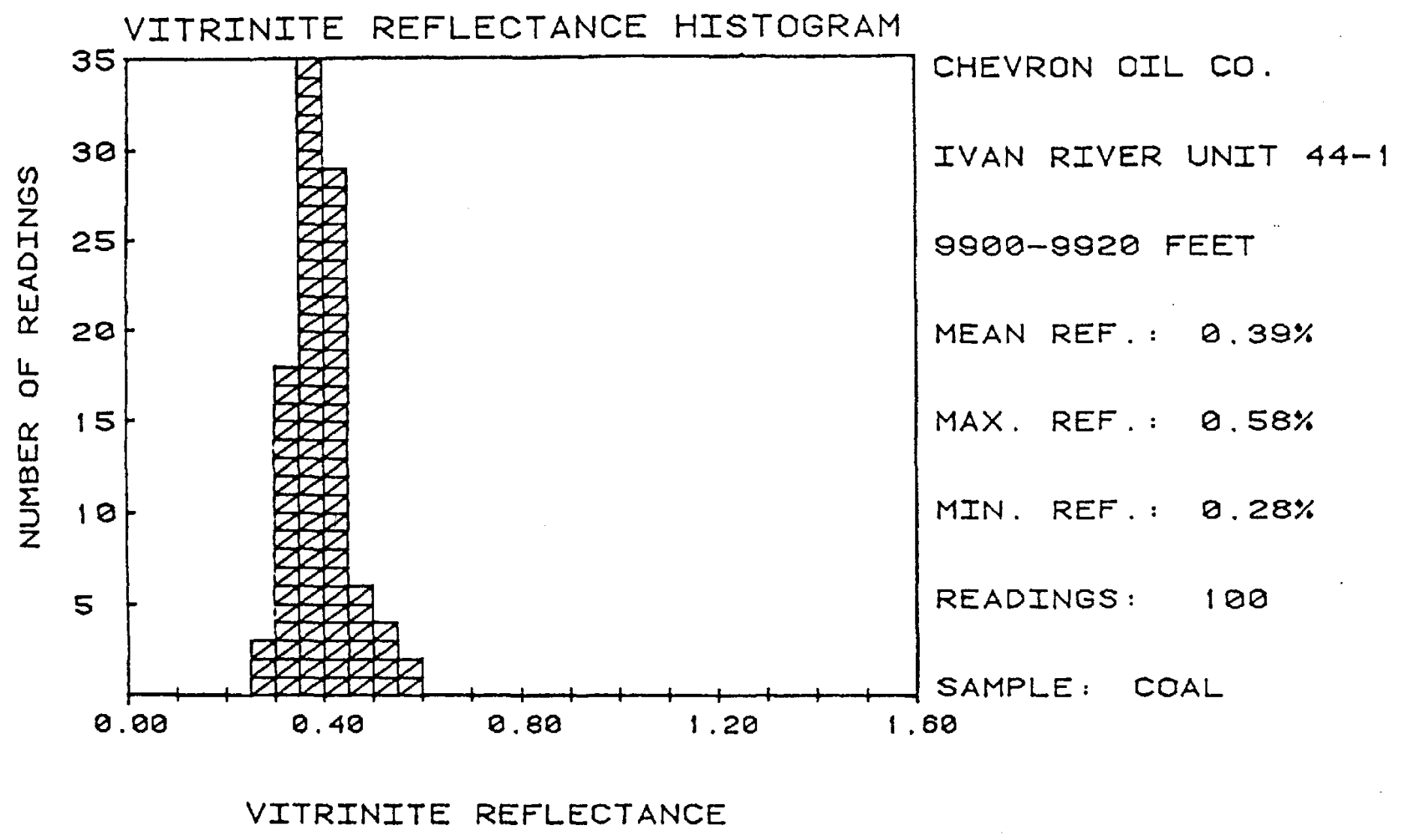

VITRINITE REFLECTANCE DATA

2o C:

0.250

0.313

$0.3 ; 9$

$\begin{array}{ll}0.43 & 1 \\ 0.49 & 1 \\ 0.55 & 0\end{array}$
Ro Ct.

$0.26 \quad 0$

0.322

0.386

0.446

$\begin{array}{ll}0.50 & 2 \\ 0.56 & 1\end{array}$

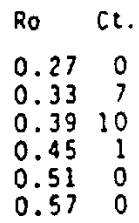

$\begin{array}{lr}\text { Ro } & \text { Ct. } \\ 0.27 & 0 \\ 0.33 & 7 \\ 0.39 & 10 \\ 0.45 & 1 \\ 0.51 & 0 \\ 0.57 & 0\end{array}$

Ro $\quad$ t

0.282

$0.34 \quad 4$

0.407

$0.46 \quad 4$

$\begin{array}{ll}0.52 & 0 \\ 0.58 & 1\end{array}$

$\begin{array}{ll}\text { Ro } & \text { Ct. } \\ 0.29 & 1 \\ 0.35 & 5 \\ 0.41 & 3 \\ 0.47 & 0 \\ 0.53 & 1 \\ 0.00 & 0\end{array}$

$\begin{array}{ll}\text { Ro } & C t . \\ 0.30 & 2 \\ 0.36 & 8 \\ 0.42 & 9 \\ 0.48 & 0 \\ 0.54 & 1 \\ 0.00 & 0\end{array}$ 


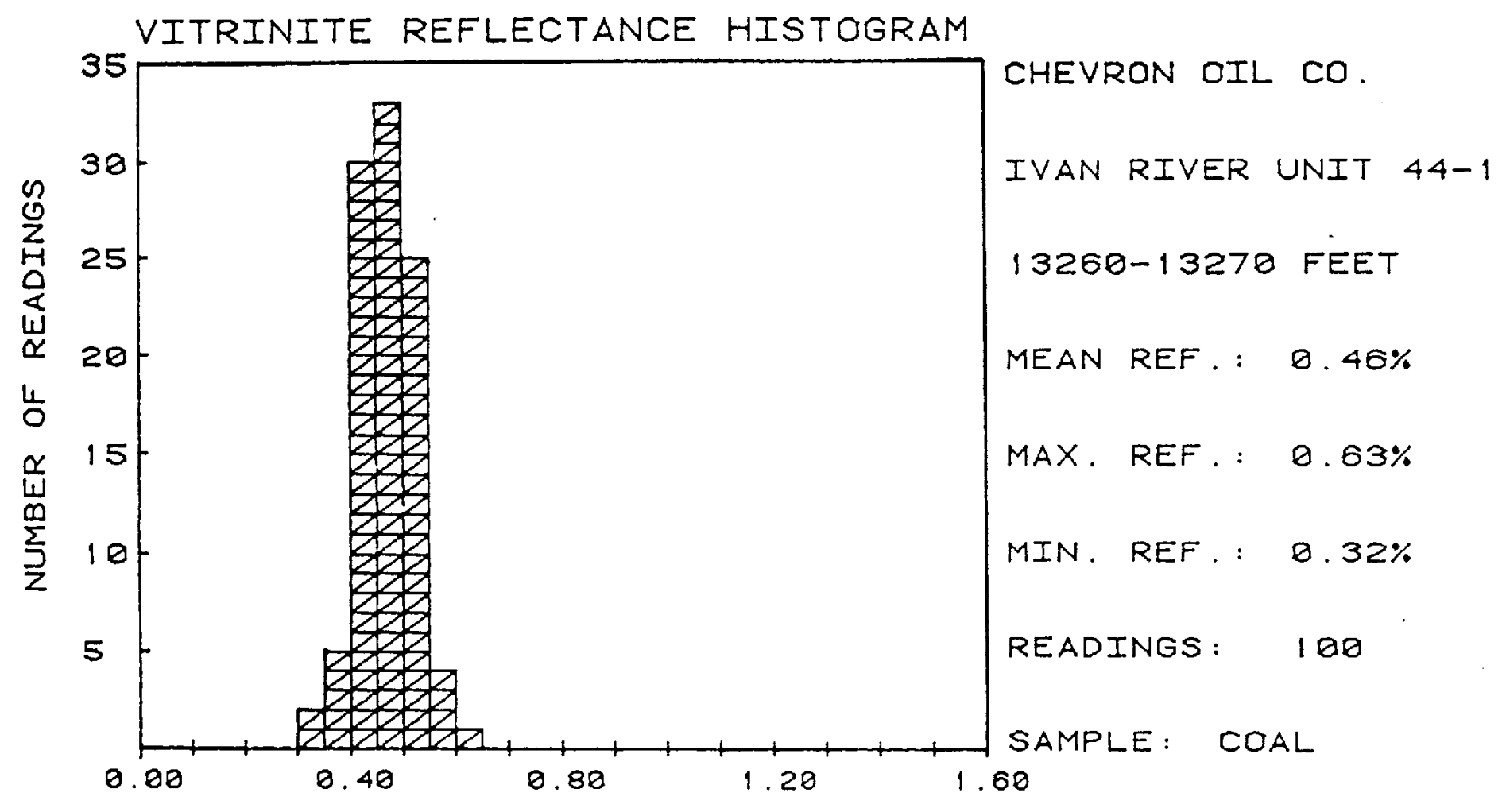

VITRINITE REFLECTANCE

VITRINITE REFLECTANCE DATA

\begin{tabular}{|c|c|c|c|c|c|c|c|c|c|c|c|}
\hline Ro & ce. & Ro & ct. & Ro & Ce. & Ro & Ct. & Ro & $c t$. & Ro & $C t$. \\
\hline $\begin{array}{l}0.30 \\
0.36 \\
0.42 \\
0.48 \\
0.54 \\
0.60\end{array}$ & $\begin{array}{l}0 \\
0 \\
5 \\
4 \\
4 \\
0\end{array}$ & $\begin{array}{l}0.31 \\
0.37 \\
0.431 \\
0.49 \\
0.55 \\
0.61\end{array}$ & $\begin{array}{r}0 \\
2 \\
10 \\
7 \\
1 \\
0\end{array}$ & $\begin{array}{l}0.32 \\
0.38 \\
0.44 \\
0.50 \\
0.56 \\
0.52\end{array}$ & $\begin{array}{l}1 \\
0 \\
3 \\
8 \\
0 \\
0\end{array}$ & $\begin{array}{l}0.33 \\
0.39 \\
0.45 \\
0.51 \\
0.57 \\
0.63\end{array}$ & $\begin{array}{l}1 \\
3 \\
9 \\
4 \\
0 \\
1\end{array}$ & $\begin{array}{l}0.34 \\
0.40 \\
0.46 \\
0.52 \\
0.58 \\
0.00\end{array}$ & $\begin{array}{l}0 \\
3 \\
7 \\
4 \\
0 \\
0\end{array}$ & $\begin{array}{l}0.35 \\
0.41 \\
0.47 \\
0.53 \\
0.59 \\
0.00\end{array}$ & $\begin{array}{l}0 \\
9 \\
6 \\
5 \\
3 \\
0\end{array}$ \\
\hline
\end{tabular}




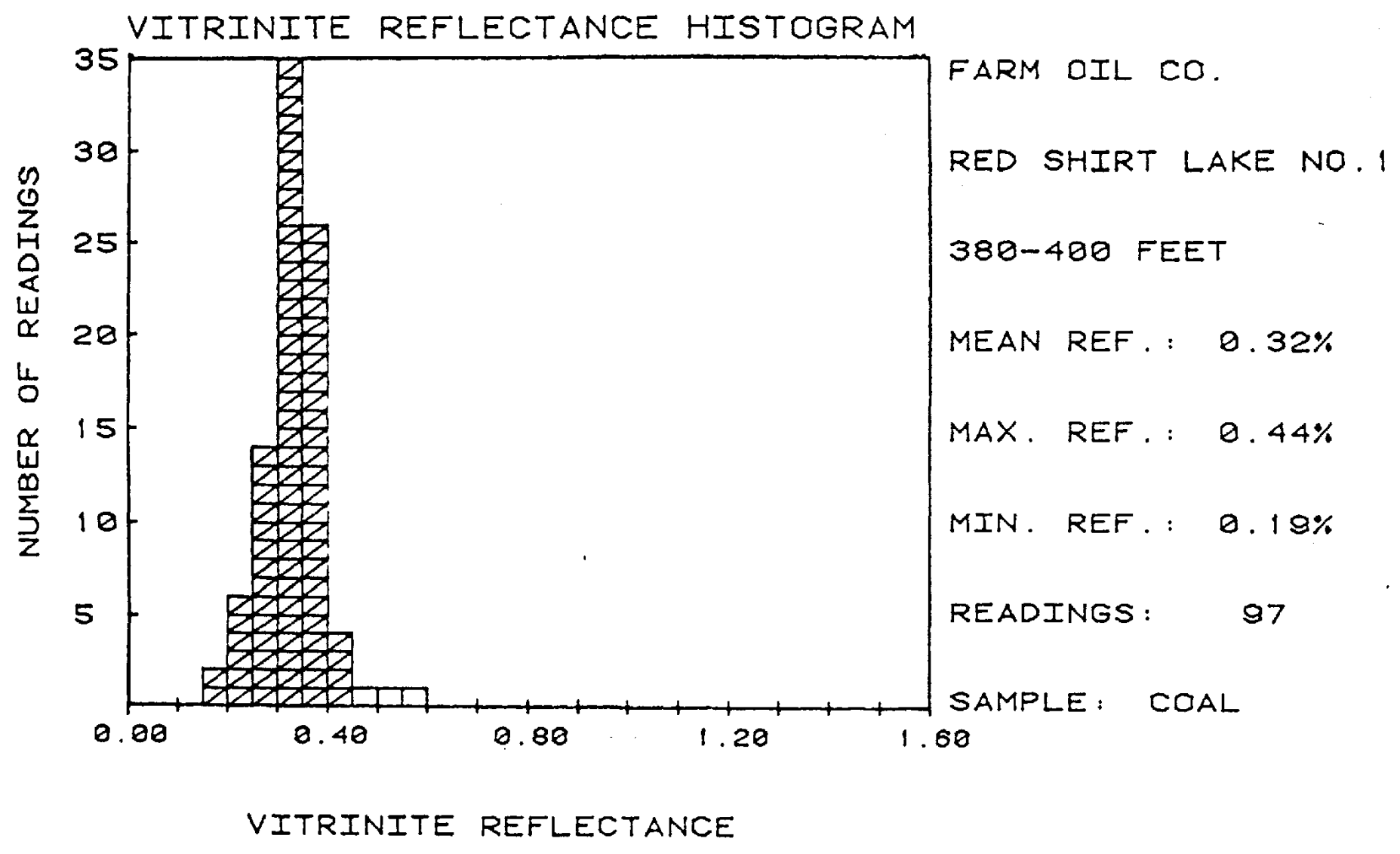

VITRINITE REFLECTANCE DATA
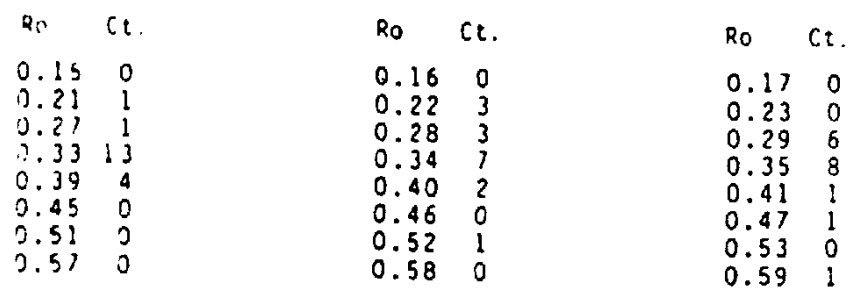

$\begin{array}{cc}\text { Ro } & C t . \\ 0.18 & 0 \\ 0.24 & 0 \\ 0.30 & 8 \\ 0.36 & 2 \\ 0.42 & 0 \\ 0.4 B & 0 \\ 0.54 & 0 \\ 0.00 & 0\end{array}$

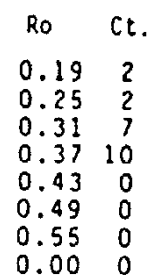

$\begin{array}{lr}\text { Ro } & C \mathrm{t} . \\ 0.20 & 2 \\ 0.26 & 2 \\ 0.32 & 10 \\ 0.38 & 2 \\ 0.44 & 1 \\ 0.50 & 0 \\ 0.56 & 0 \\ 0.00 & 0\end{array}$ 


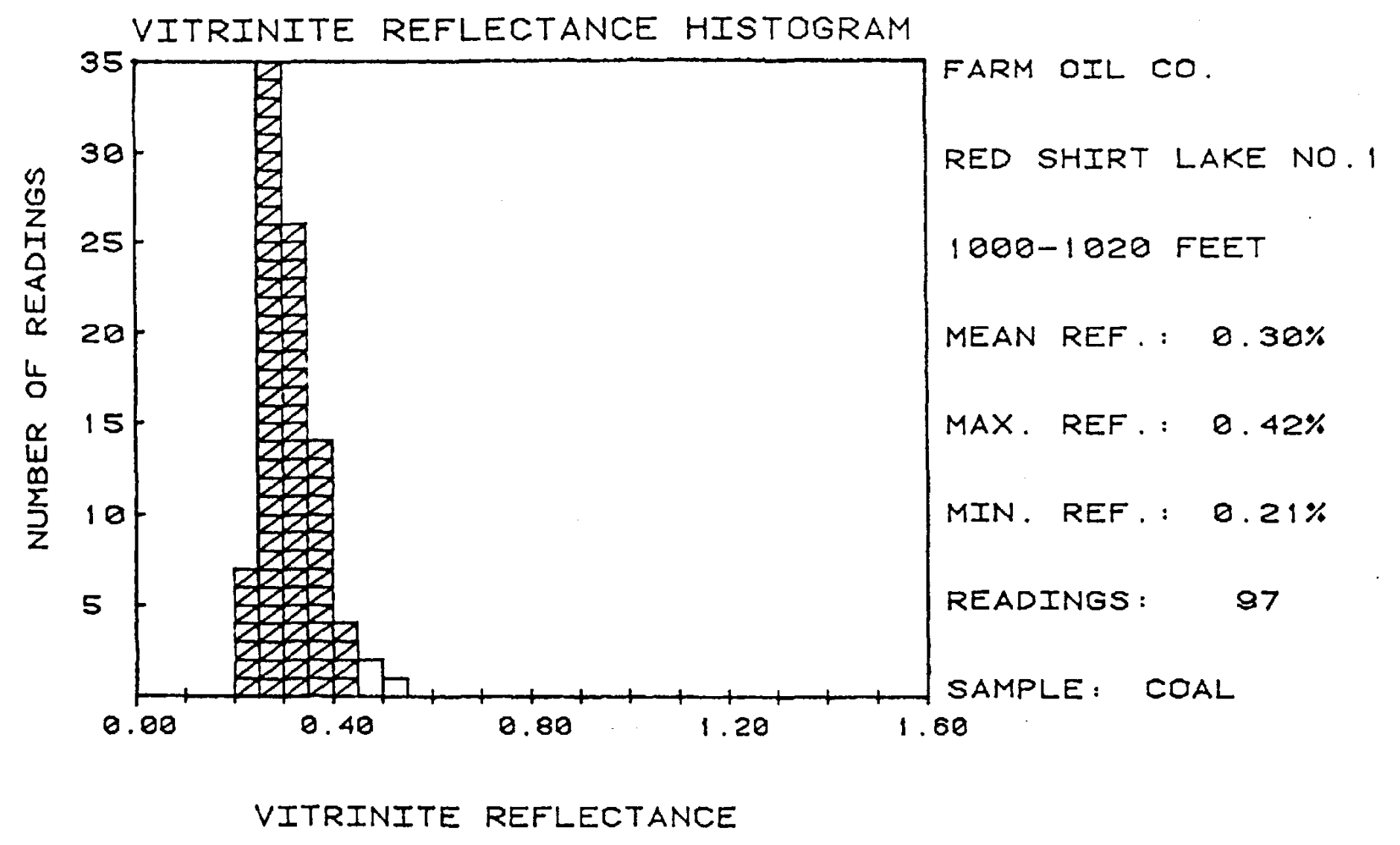

VITRINITE REFLECTANCE DATA

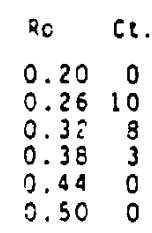

$$
\begin{array}{lr}
\text { Ro } & C t . \\
0.21 & 1 \\
0.27 & 12 \\
0.33 & 2 \\
0.39 & 2 \\
0.45 & 0 \\
0.51 & 1
\end{array}
$$
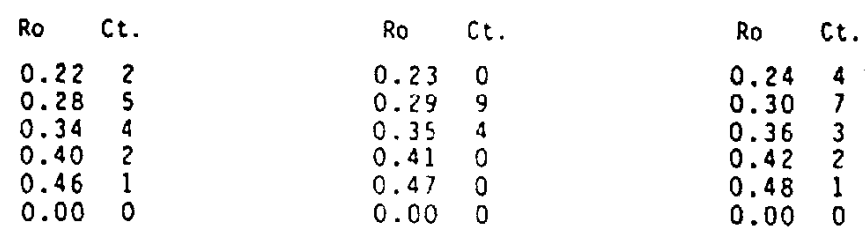

Ro Ct.

0.2510

0.315

0.372

0.430

$\begin{array}{ll}0.49 & 0 \\ 0.00 & 0\end{array}$ 


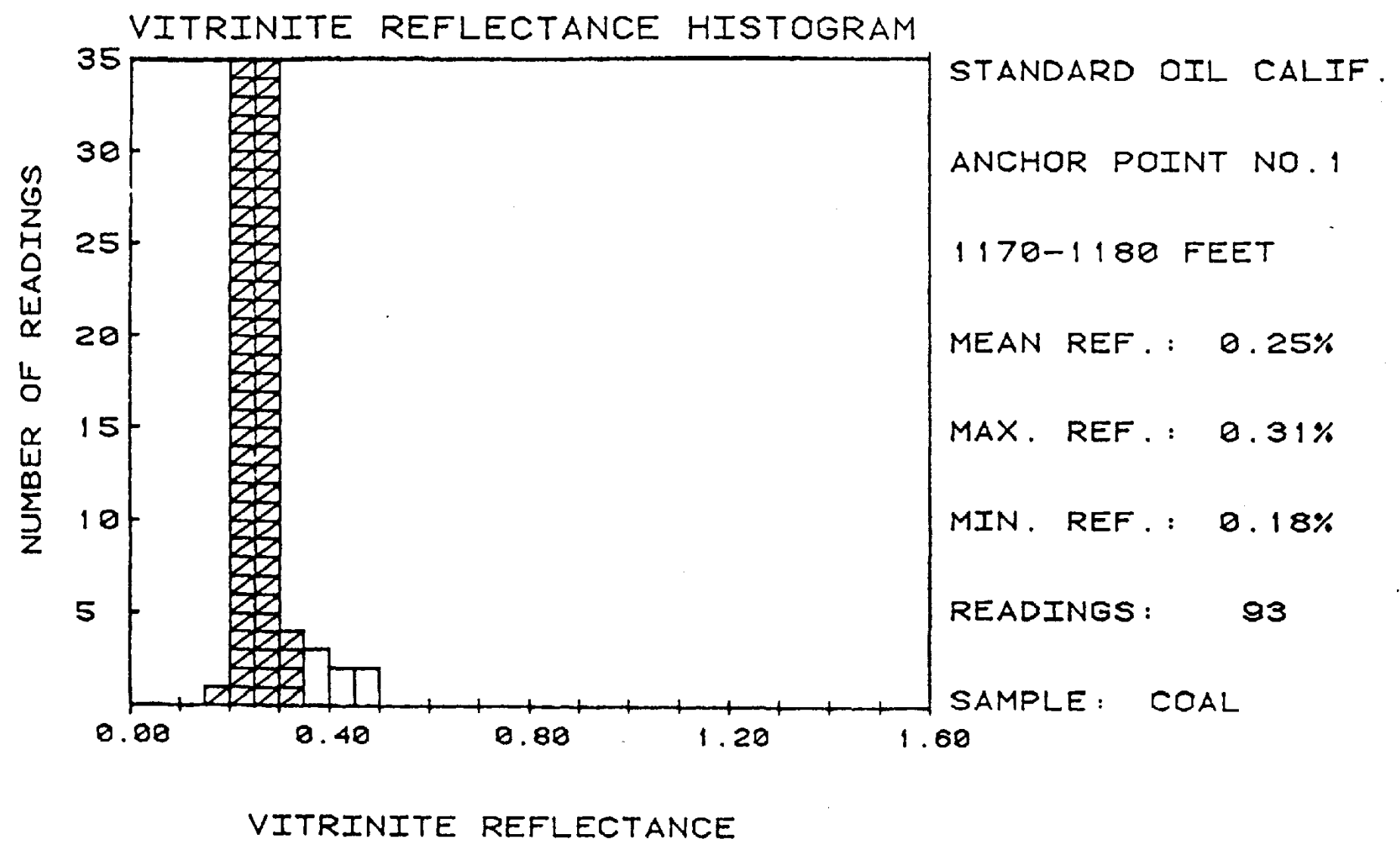

VITRINITE REFLECTANCE DATA

$\begin{array}{ll}\text { Ro } & C 2 \\ 0.15 & 0 \\ 0.21 & 3 \\ 0.27 & 8 \\ 0.33 & 0 \\ 0.39 & 1 \\ 0.45 & 2\end{array}$

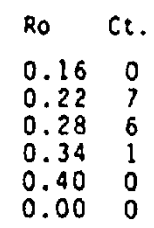

$\begin{array}{lr}\text { Ro } & C t . \\ 0.17 & 0 \\ 0.23 & 21 \\ 0.29 & 4 \\ 0.35 & 0 \\ 0.41 & 1 \\ 0.00 & 0\end{array}$

$\begin{array}{lc}\text { Ro } & C t . \\ 0.18 & 1 \\ 0.24 & 14 \\ 0.30 & 2 \\ 0.36 & 1 \\ 0.42 & 0 \\ 0.00 & 0\end{array}$

$\begin{array}{lr}\text { Ro } & C t . \\ 0.19 & 0 \\ 0.25 & 13 \\ 0.31 & 1 \\ 0.37 & 0 \\ 0.43 & 0 \\ 0.00 & 0\end{array}$

$\begin{array}{lr}\text { Ro } & C t . \\ 0.20 & 2 \\ 0.26 & 11 \\ 0.32 & 0 \\ 0.38 & 1 \\ 0.44 & 1 \\ 0.00 & 0\end{array}$ 


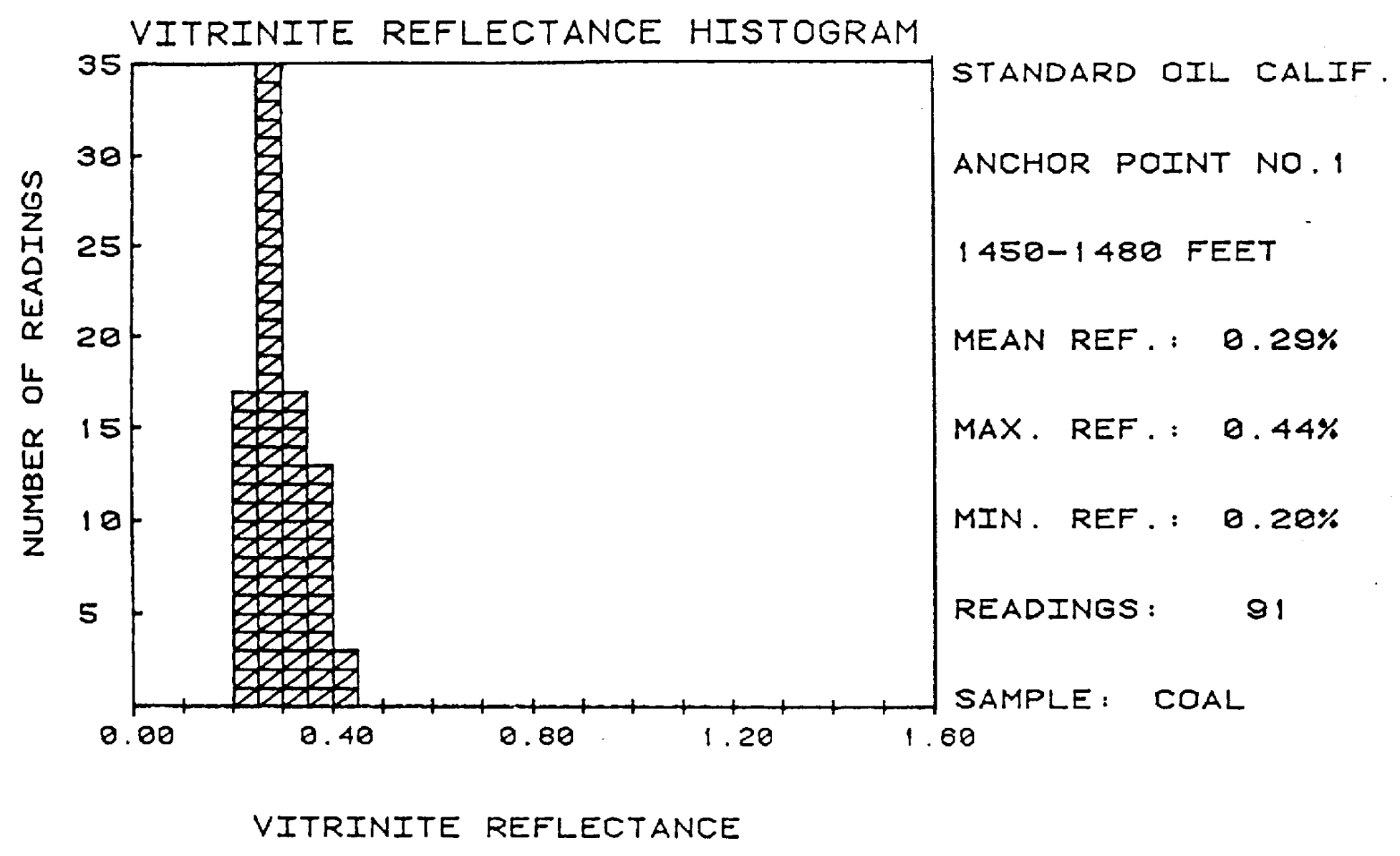

VITRINITE REFLECTANCE DATA

$\begin{array}{ll}80 & C l \\ 0.15 & 0 \\ 0.21 & 3 \\ 0.27 & 5 \\ 0.33 & 2 \\ 0.39 & 1\end{array}$

$\begin{array}{ll}\text { Ro } & C t . \\ 0.16 & 0 \\ 0.22 & 5 \\ 0.28 & 9 \\ 0.34 & 2 \\ 0.40 & 0\end{array}$

$\begin{array}{ll}\text { Ro } & C t . \\ 0.17 & 0 \\ 0.23 & 4 \\ 0.29 & 5 \\ 0.35 & 3 \\ 0.41 & 1\end{array}$

$\begin{array}{ll}\text { Ro } & c t . \\ 0.18 & 0 \\ 0.24 & 4 \\ 0.30 & 5 \\ 0.36 & 4 \\ 0.42 & 0\end{array}$

$\begin{array}{ll}\text { Ro } & \text { Ct. } \\ 0.19 & 0 . \\ 0.25 & 9 \\ 0.31 & 5 \\ 0.37 & 3 \\ 0.43 & 0\end{array}$

Ro $\mathrm{Ct}$.

0.201

$0.26 \quad 13$

0.323

$\begin{array}{ll}0.38 & 2 \\ 0.44 & 2\end{array}$ 


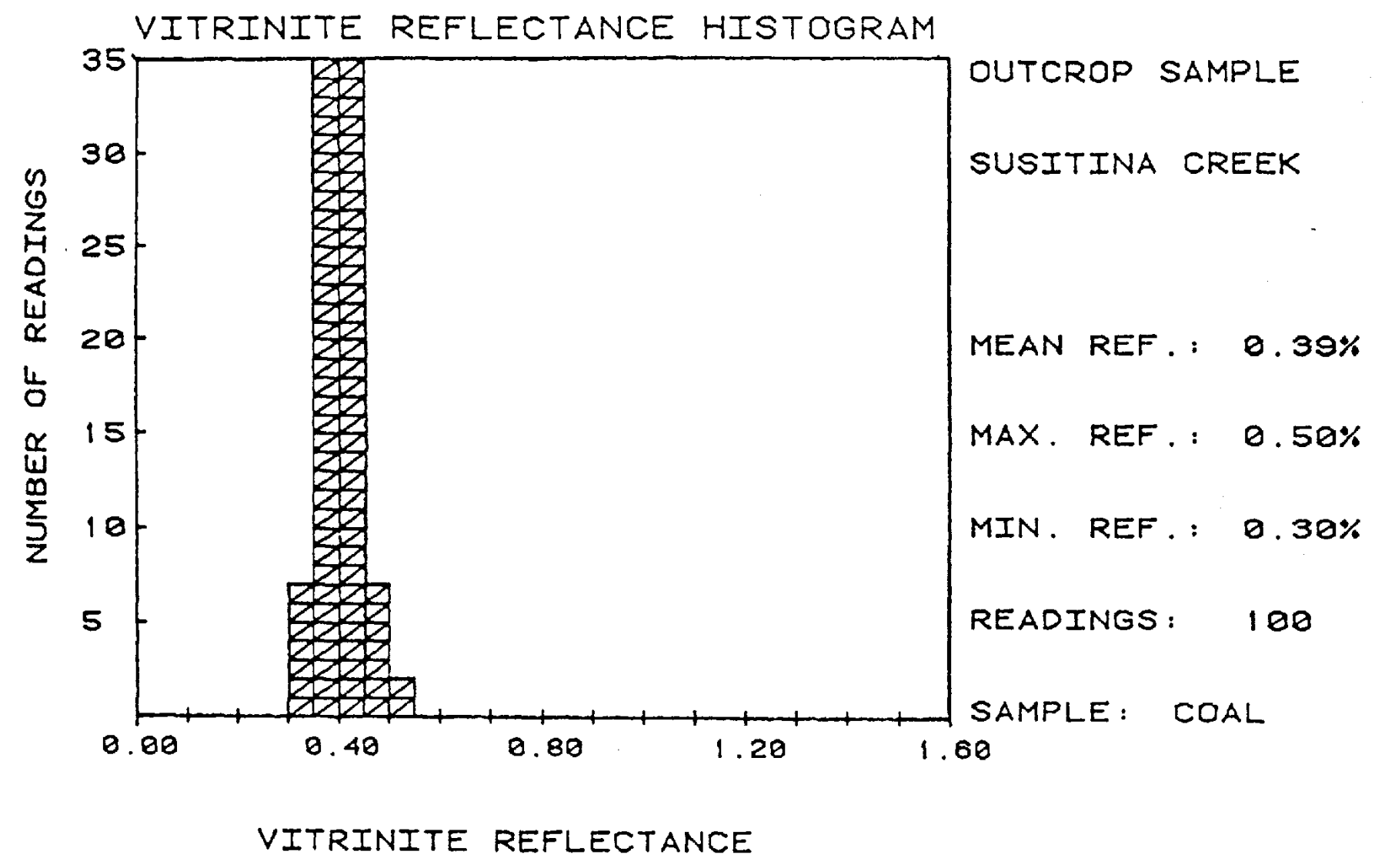

VITRINITE REFLECTANCE DATA

$\begin{array}{lr}2 c & C 6 . \\ 0.25 & 0 \\ 0.31 & 0 \\ 0.37 & 13 \\ 0.43 & 10 \\ 0.49 & 0\end{array}$

$\begin{array}{ll}\text { Ro } & C t \\ 0.26 & 0 \\ 0.32 & 1 \\ 0.38 & 8 \\ 0.44 & 5 \\ 0.50 & 2\end{array}$

$\begin{array}{lr}\text { Ro } & \text { Ct. } \\ 0.27 & 0 \\ 0.33 & 2 \\ 0.39 & 11 \\ 0.45 & 3 \\ 0.00 & 0\end{array}$

$\begin{array}{ll}20 & C t \\ 0.29 & 0 \\ 0.34 & 3 \\ 0.40 & 9 \\ 0.46 & 0 \\ 0.00 & 0\end{array}$

$\begin{array}{lc}\text { Ro } & C t . \\ 0.29 & 0 \\ 0.35 & 8 \\ 0.41 & 9 \\ 0.47 & 1 \\ 0.00 & 0\end{array}$

$\begin{array}{ll}\text { Ro } & C t . \\ 0.30 & 1 \\ 0.36 & ? \\ 0.42 & 4 \\ 0.48 & 3 \\ 0.00 & 0\end{array}$ 


\section{REFLECTANCE ANALYSIS}

WAL Batch: 8423-110-06

Report of Analysis on Sample: Arco Rainbow \#1 1095 - 1124 ft Mean-Maximum Vitrinite Ro: 0.18

Distribution of Vitrinite Reflectance Readings:

\%Ro

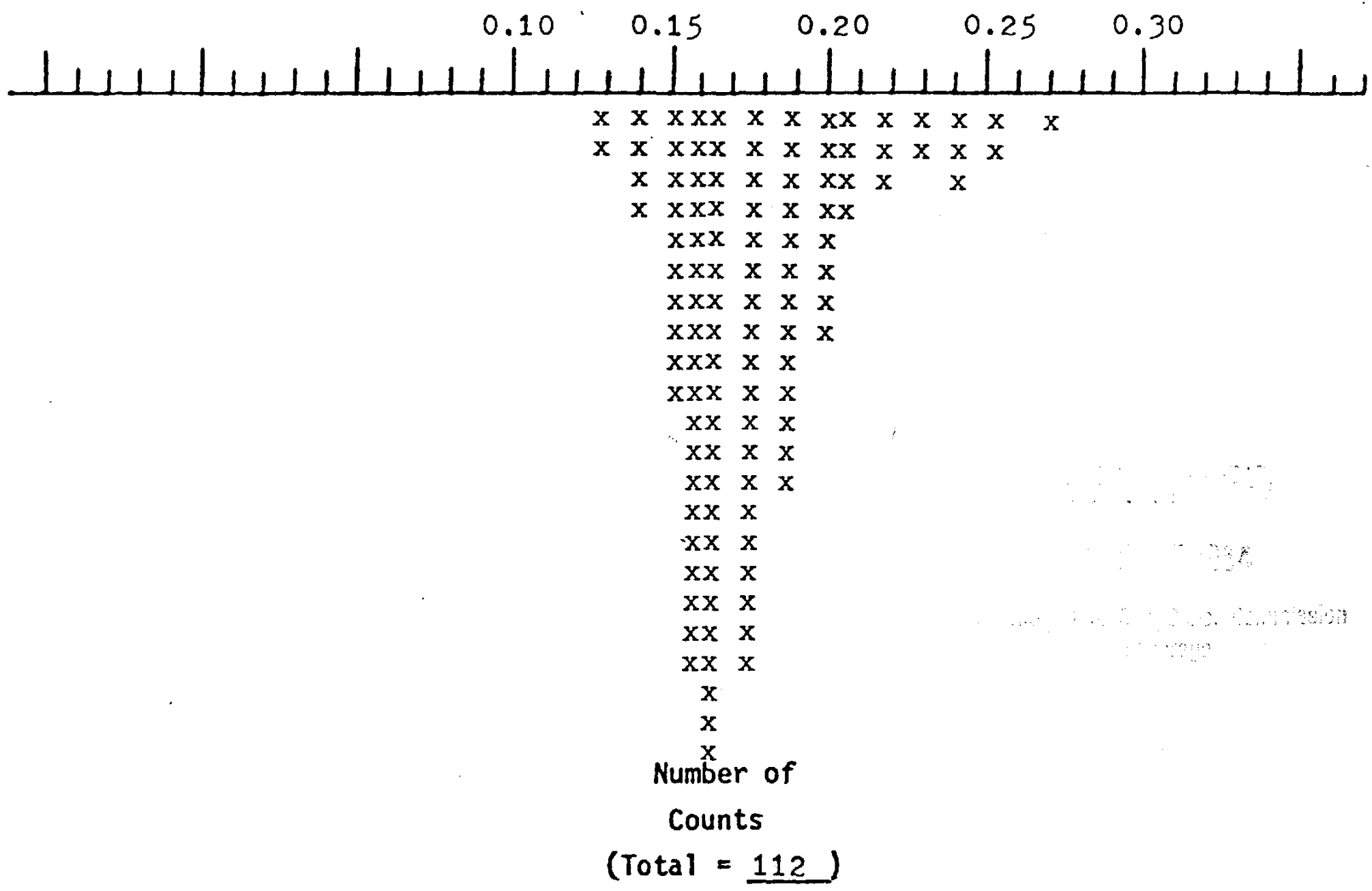

$y$-Type Table for Vitrinites $(=100 \%)$

$\frac{v-1}{79.5} \frac{v-2}{20.5} \quad \underline{v} \quad \underline{v}$




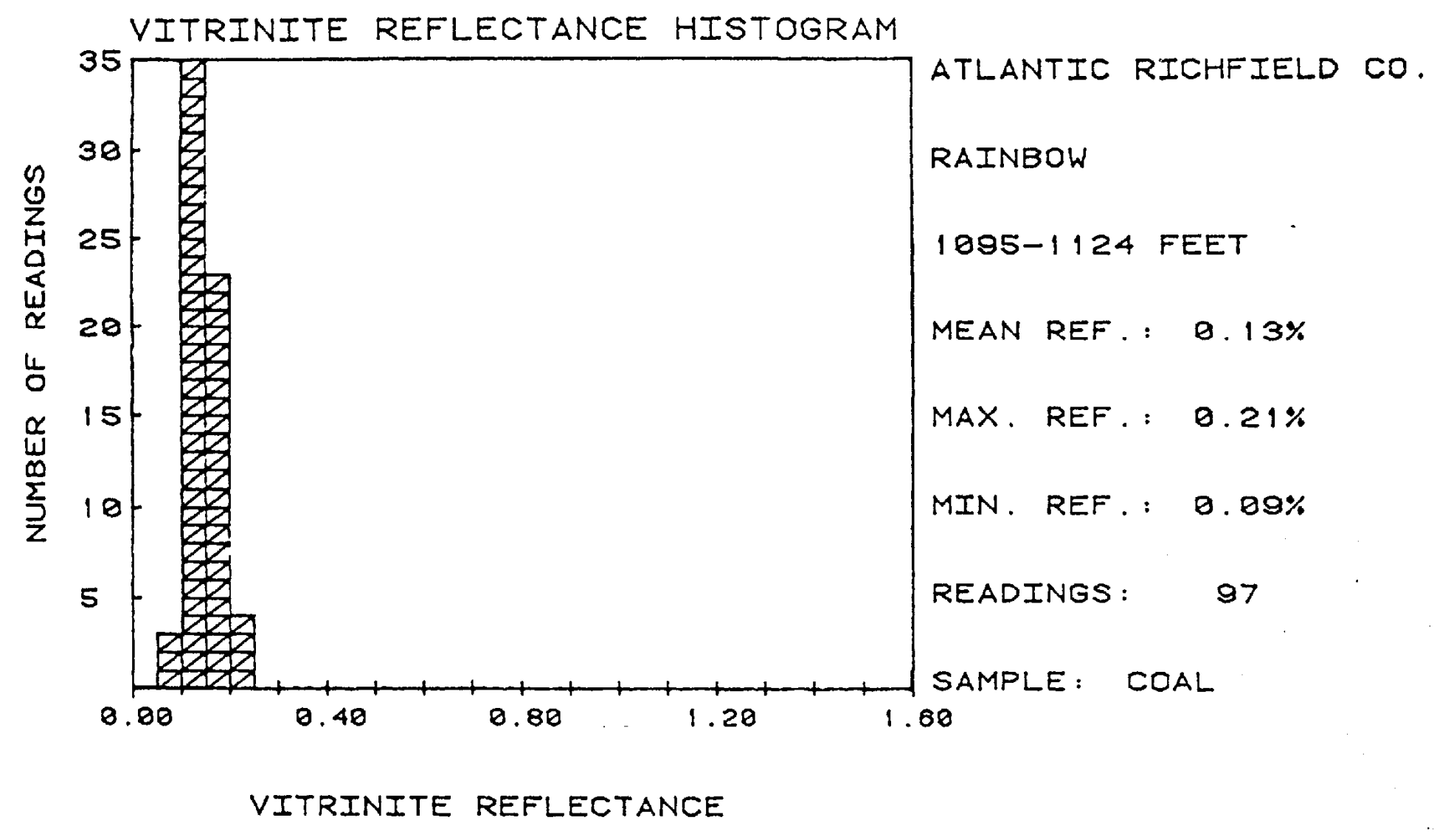

VITRINITE REFLECTANCE DATA
Ro $\mathrm{Ct}$.
Ro Ct.
Ro $c t$.
$\begin{array}{ll}\text { Ro } & C t . \\ 0.08 & 0 \\ 0.14 & 9 \\ 0.20 & 2\end{array}$
Ro Ct.
0.093
0.1311
$\begin{array}{ll}0.15 & 5 \\ 0.21 & 2\end{array}$
$\begin{array}{lr}\text { Ro } & C_{t} \\ 0.10 & 15 \\ 0.16 & 5 \\ 0.00 & 0\end{array}$ 


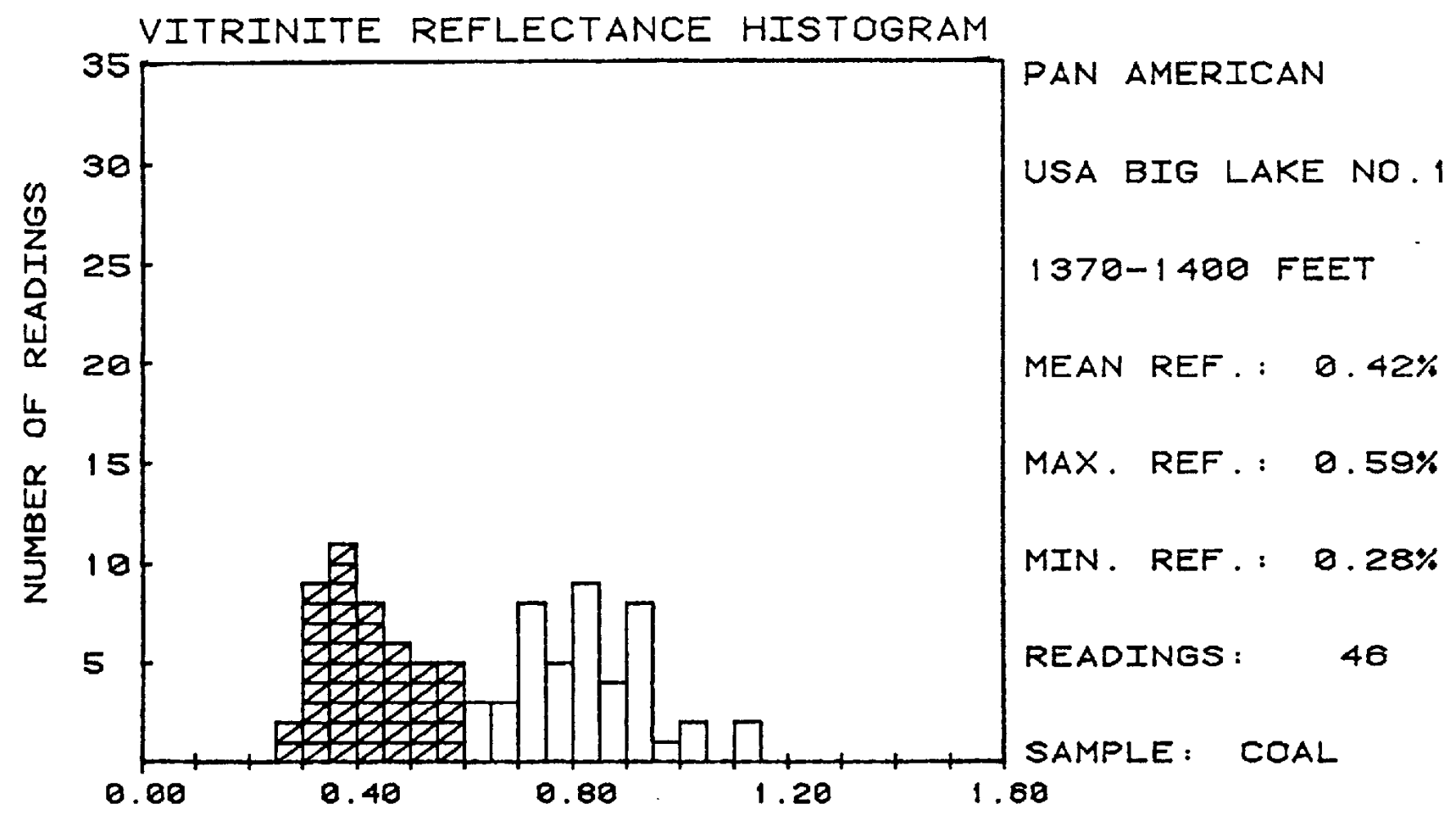

VITRINITE REFLECTANCE

VITRINITE REFLECTANCE DATA
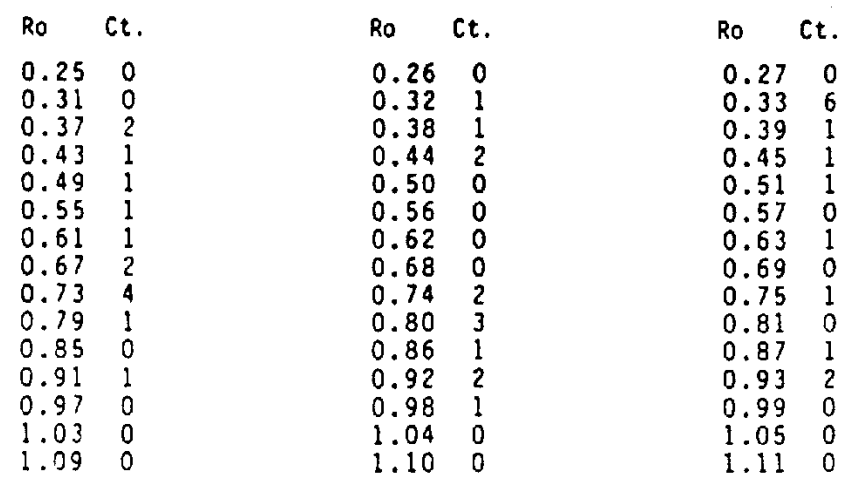

$\begin{array}{ll}\text { Ro } & C t . \\ 0.28 & 1 \\ 0.34 & 2 \\ 0.40 & 0 \\ 0.46 & 2 \\ 0.52 & 0 \\ 0.58 & 1 \\ 0.64 & 1 \\ 0.70 & 0 \\ 0.76 & 3 \\ 0.82 & 2 . \\ 0.88 & 1 \\ 0.94 & 1 \\ 1.00 & 2 \\ 1.06 & 0 \\ 1.12 & 2\end{array}$

$\begin{array}{ll}\text { Ro } & \text { Ct. } \\ 0.29 & 1 \\ 0.35 & 6 \\ 0.41 & 2 \\ 0.47 & 0 \\ 0.53 & 1 \\ 0.59 & 3 \\ 0.65 & 1 \\ 0.71 & 0 \\ 0.77 & 0 \\ 0.83 & 3 \\ 0.89 & 1 \\ 0.95 & 0 \\ 1.01 & 0 \\ 1.07 & 0 \\ 0.00 & 0\end{array}$

$\begin{array}{ll}\text { Ro } & \mathrm{Ct} . \\ 0.30 & 0 \\ 0.36 & 1 \\ 0.42 & 3 \\ 0.48 & 2 \\ 0.54 & 3 \\ 0.60 & 0 \\ 0.66 & 0 \\ 0.72 & 2 \\ 0.78 & 0 \\ 0.84 & 1 \\ 0.90 & 2 \\ 0.96 & 0 \\ 1.02 & 0 \\ 1.08 & 0 \\ 0.00 & 0\end{array}$ 


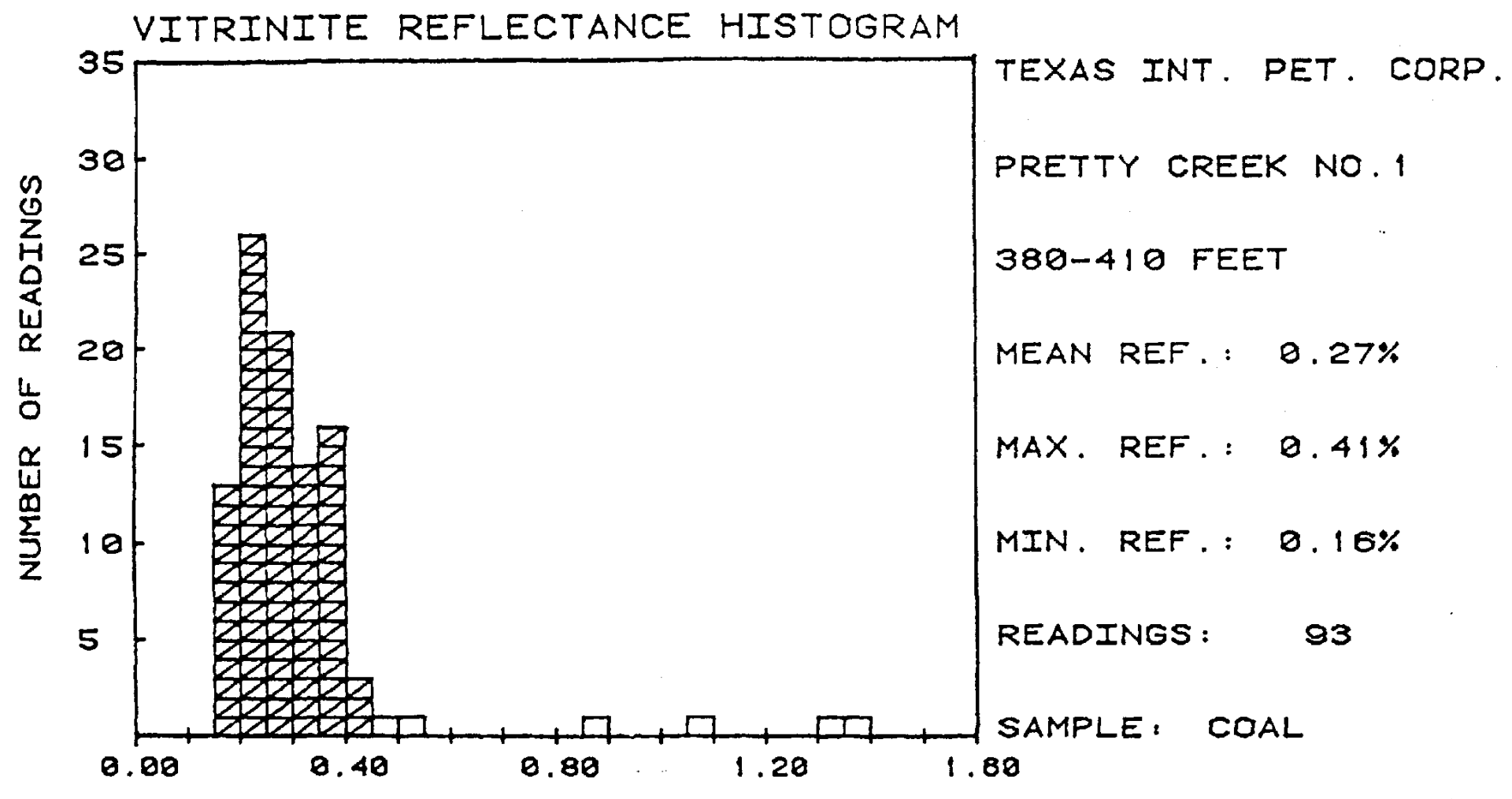

VITRINITE REFLECTANCE

VITRINITE REFLECTANCE DATA 


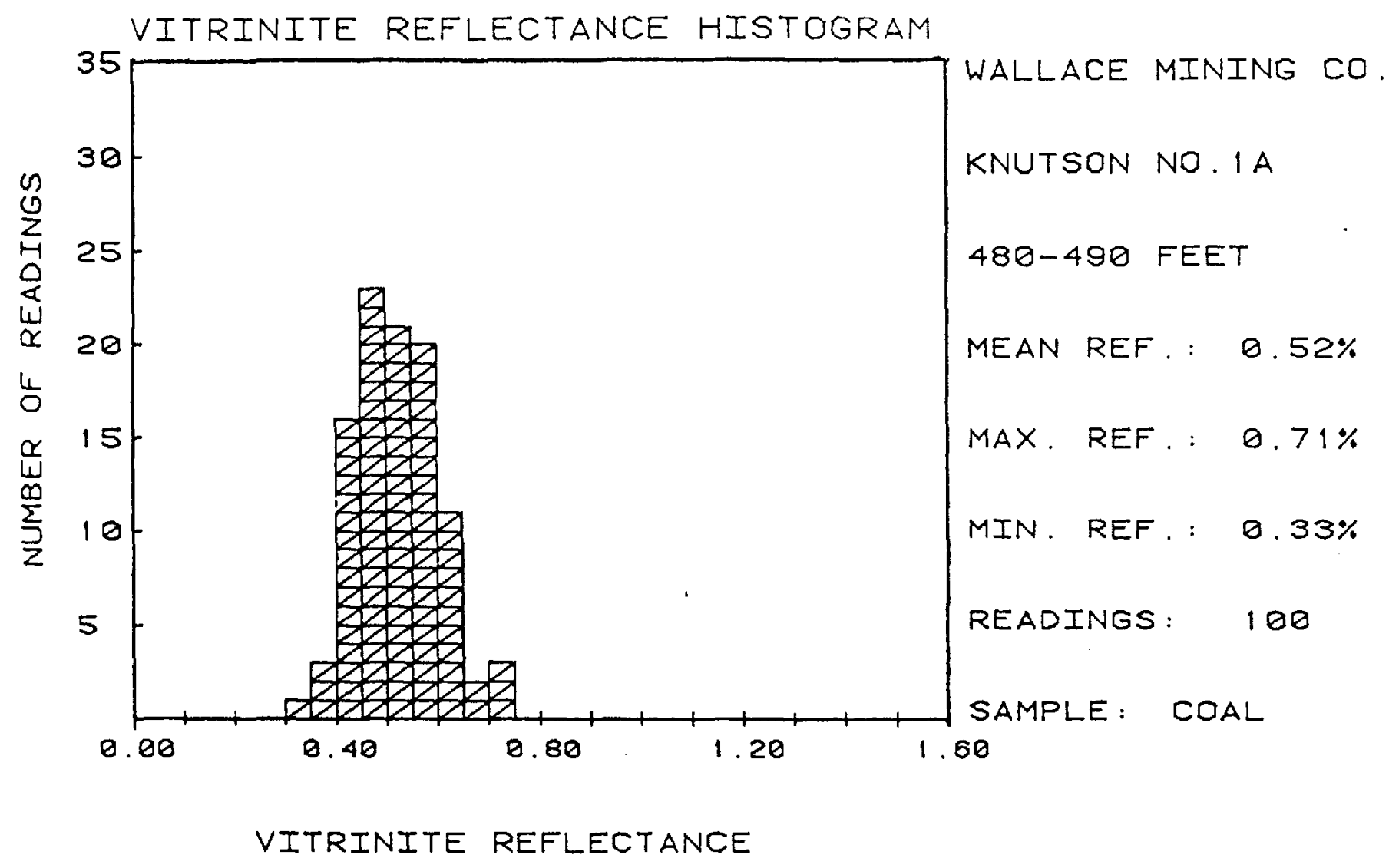

VITRINITE REFLECTANCE DATA
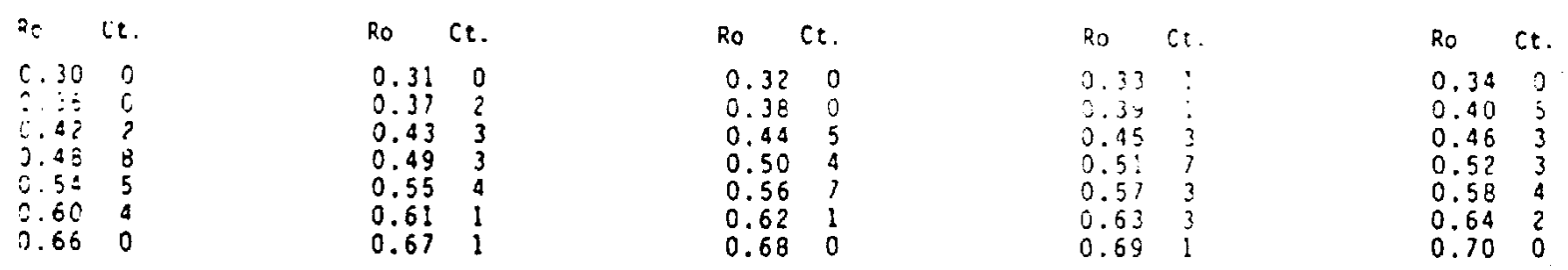

$\begin{array}{ll}\text { Ro } & \text { Ct. } \\ 0.35 & 0 \\ 0.41 & 1 \\ 0.47 & 6 \\ 0.53 & 2 \\ 0.59 & 2 \\ 0.65 & 0 \\ 0.71 & 3\end{array}$ 


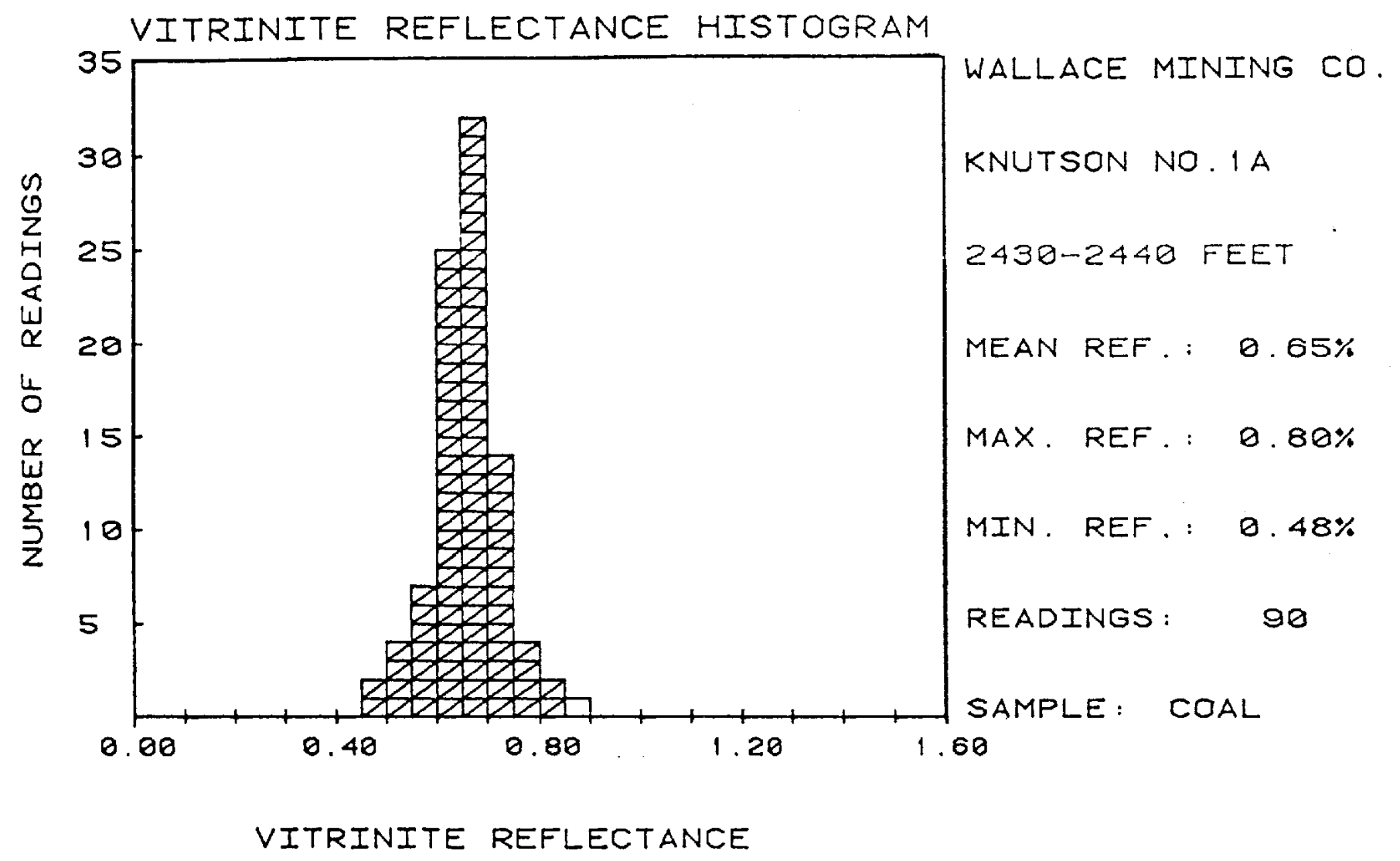

VITRINITE REFLECTANCE DATA
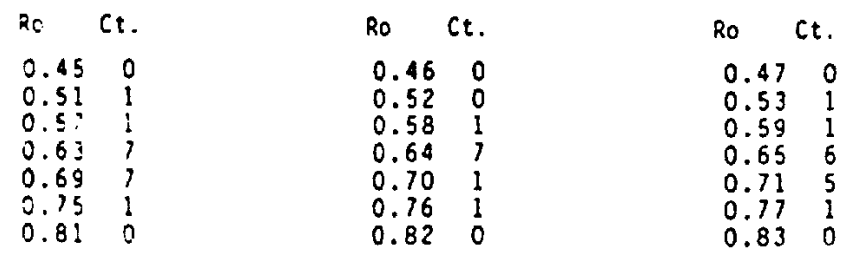

$\begin{array}{lc}\text { Ro } & C t . \\ 0.48 & 2 \\ 0.54 & 2 \\ 0.60 & 2 \\ 0.66 & 5 \\ 0.72 & 6 \\ 0.78 & 0 \\ 0.84 & 0\end{array}$

$\begin{array}{lc}\text { Ro } & C t . \\ 0.49 & 0 \\ 0.55 & 3 \\ 0.61 & 7 \\ 0.67 & 7 \\ 0.73 & 0 \\ 0.79 & 1 \\ 0.85 & 0\end{array}$

$\begin{array}{lr}\text { Ro } & \text { Ct. } \\ 0.50 & 0 \\ 0.56 & 1 \\ 0.62 & 2 \\ 0.68 & 7 \\ 0.74 & 2 \\ 0.80 & 2 \\ 0.86 & 1\end{array}$ 


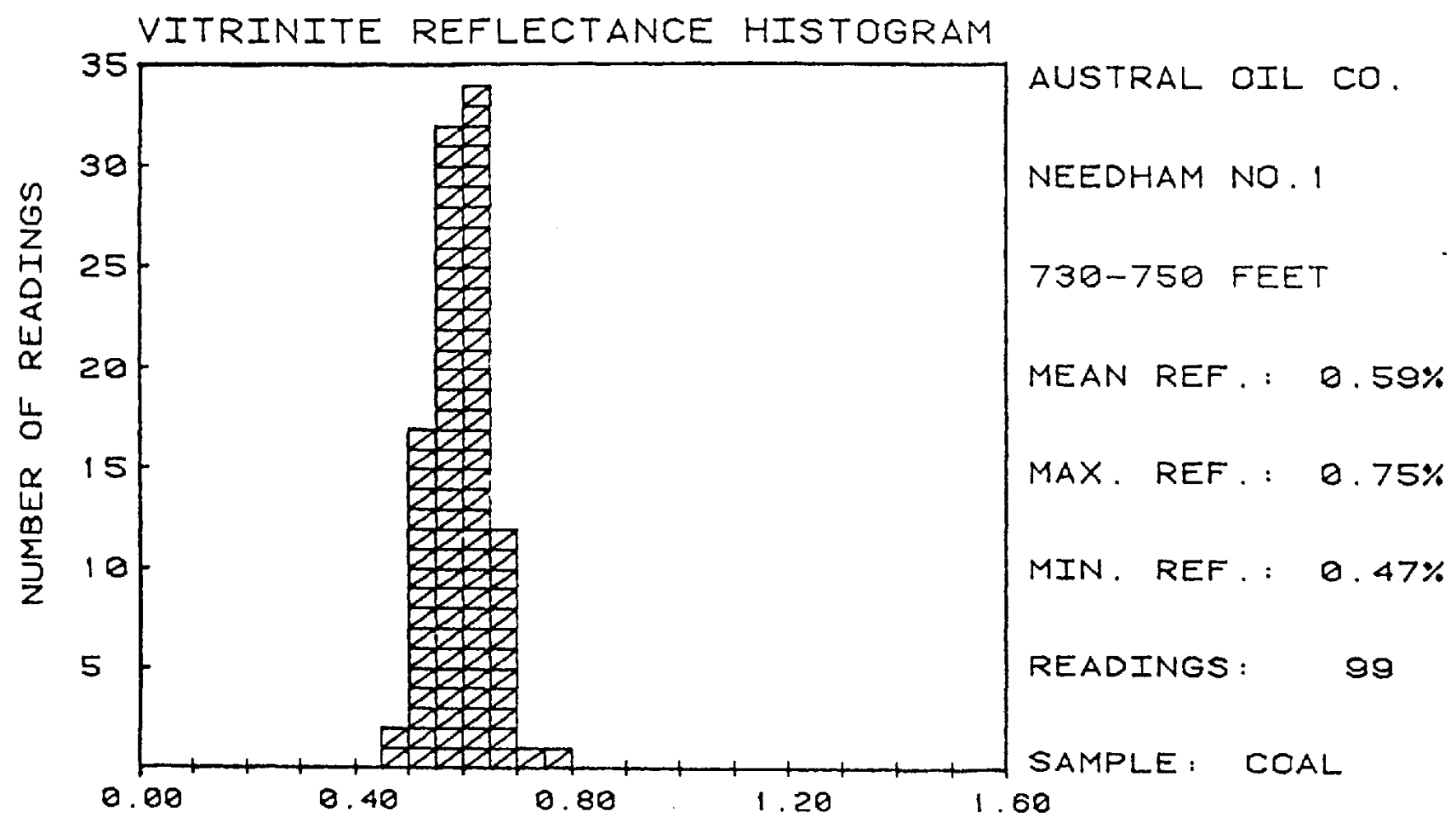

VITRINITE REFLECTANCE

VITRINITE REFLECTANCE DATA

$\begin{array}{ll}R_{C} & C l . \\ 0.45 & 0 \\ 0.51 & 2 \\ 0.57 & 9 \\ 0.63 & 9 \\ 0.69 & 3 \\ 0.75 & 1\end{array}$

$\begin{array}{ll}\text { Ro } & \text { Ct. } \\ 0.46 & 0 \\ 0.52 & 4 \\ 0.58 & 5 \\ 0.64 & ? \\ 0.70 & 1 \\ 0.00 & 0\end{array}$

$\begin{array}{lr}\text { Ro } & \text { Ct. } \\ 0.47 & 1 \\ 0.53 & 1 \\ 0.59 & 10 \\ 0.65 & 2 \\ 0.71 & 0 \\ 0.00 & 0\end{array}$

$\begin{array}{lr}\text { Ro } & C t . \\ 0.48 & 0 \\ 0.54 & 8 \\ 0.60 & 12 \\ 0.66 & 2 \\ 0.72 & 0 \\ 0.00 & 0\end{array}$

$\begin{array}{ll}\text { Ro } & \text { Ct. } \\ 0.49 & 1 \\ 0.55 & 5 \\ 0.61 & 1 \\ 0.67 & 3 \\ 0.73 & 0 \\ 0.00 & 0\end{array}$

$\begin{array}{ll}\text { Ro } & \text { Ct. } \\ 0.50 & 2 \\ 0.56 & 3 \\ 0.62 & 9 \\ 0.68 & 2 \\ 0.74 & 0 \\ 0.00 & 0\end{array}$ 